\title{
Progress and prospects of applied research on physical geography and the living environment in China over the past 70 years (1949-2019)
}

CHEN Fahu ${ }^{1,2,3}$, "WU Shaohong ${ }^{3,4,5}$, CUI Peng ${ }^{2,3,6}$, CAI Yunlong ${ }^{7}$, ZHANG Yili ${ }^{2,3,4,5}$, YIN Yunhe ${ }^{4,5}$, LIU Guobin ${ }^{8}$, OUYANG Zhu ${ }^{3,4}$, MA Wei ${ }^{9}$, YANG Linsheng ${ }^{3,4,5}$, WU Duo ${ }^{10}$, LEI Jiaqiang ${ }^{11}$, ZHANG Guoyou ${ }^{4,12}$, ZOU Xueyong ${ }^{13}$, CHEN Xiaoqing ${ }^{2,6}$, TAN Minghong ${ }^{3,4,5}$, WANG Xunming ${ }^{3,4}$, BAO Anming ${ }^{11}$, CHENG Weixin ${ }^{4}$, DANG Xiaohu ${ }^{14}$, WEI Binggan ${ }^{4,5}$, WANG Guoliang ${ }^{8}$, WANG Wuyi ${ }^{4,5}$, ZHANG Xingquan ${ }^{4}$, LIU Xiaochen ${ }^{2,15}$, LI Shengyu ${ }^{11}$

1. Key Laboratory of Alpine Ecology, Institute of Tibetan Plateau Research, CAS, Beijing 100101, China;

2. CAS Centre for Excellence in Tibetan Plateau Earth Sciences, Beijing 100101, China;

3. College of Resources and Environment, University of Chinese Academy of Sciences, Beijing 100190, China;

4. Institute of Geographic Sciences and Natural Resources Research, CAS, Beijing 100101, China;

5. Key Laboratory of Land Surface Pattern and Simulation, CAS, Beijing 100101, China;

6. Institute of Mountain Hazards and Environment, CAS, Chengdu 610041, China;

7. College of Urban and Environmental Sciences, Peking University, Beijing 100871, China;

8. State Key Laboratory of Soil Erosion and Dryland Farming on the Loess Plateau, Northwest A\&F University, Yangling 712100, Shaanxi, China;

9. Northwest Institute of Eco-Environment and Resources, CAS, Lanzhou 730000, China;

10. Key Laboratory of Western China's Environmental Systems (Ministry of Education), College of Earth and

Environmental Sciences, Lanzhou University, Lanzhou 730000, China;

11. Xinjiang Institute of Ecology and Geography, CAS, Urumqi 830011, China;

12. The Geographical Society of China, Beijing 100101, China;

13. Faculty of Geographical Science, Beijing Normal University, Beijing 100875, China;

14. College of Geology and Environment, Xi'an University of Science and Technology, Xi'an 710054, China;

15. Institute of Tibetan Plateau Research, CAS, Beijing 100101, China

Abstract: Physical geography is a basic research subject of natural sciences. Its research object is the natural environment which is closely related to human living and development, and China's natural environment is complex and diverse. According to national needs and regional development, physical geographers have achieved remarkable achievements in applied basis and applied research, which also has substantially contributed to the planning of national economic growth and social development, the protection of macro ecosystems and resources, and sustainable regional development. This study summarized the practice and application of physical geography in China over the past 70 years in the following fields: regional differences in natural environments and physical regionalization; land use and land

Received: 2020-08-11 Accepted: 2020-10-08

Foundation: Key Project of National Natural Science Foundation of China, No.41530749, No.41842050

Author: Chen Fahu, Academician of Chinese Academy of Sciences, E-mail: fhchen@itpcas.ac.cn

"Corresponding author: Wu Shaohong, Professor, E-mail: wush@igsnrr.ac.cn 
cover changes; natural hazards and risk reduction; process and prevention of desertification; upgrading of medium- and low-yield fields in the Huang-Huai-Hai region; engineering construction in permafrost areas; geochemical element anomalies and the prevention and control of endemic diseases; positioning and observation of physical geographical elements; and identification of geospatial differentiation and geographical detectors. Furthermore, we have proposed the future direction of applied research in the field of physical geography.

Keywords: physical geography; scientific practice; applied research; regional development; national strategy

\section{Introduction}

Physical geography is a natural science that studies the spatial characteristics, evolutionary processes, and regional differentiation laws of the natural environment on land surface related to human living environment. It is the basic discipline and cornerstone of the comprehensive study of geography (Fu, 2018; Chen et al., 2019). The terrestrial surface system studied by physical geography is the most complex subsystem of the earth system. This subsystem is closely related to human activities and broadly concerned with the spatiotemporal structure, evolution, development, and interaction of the environment, resources, and social economy. The core of geographical sciences is the study of the interactions between natural and human elements on the land surface and their regular spatiotemporal patterns (Zheng et al., 2015). Thus, physical geography studies many significant scientific concerns pertaining to socioeconomic sustainability and involves the basis of many major social issues related to people's livelihoods. The achievements over the past 70 years have been widely utilized and have made significant contributions to the socioeconomic sustainable development.

Over the past 70 years, studies in physical geography in China have produced worldwide cutting-edge theoretical research on geographical processes and the living environment (Chen et al., 2019). Moreover, in line with the needs of national socioeconomic development, a great deal of work has been conducted in physical geography, generating outstanding achievements in the following fields: regional differences in the natural environment and physical regionalization; land use and land cover changes; natural hazards and risk governance and reduction; desertification process and prevention; upgrading of medium- and low-yield fields in the Huang-Huai-Hai region; engineering construction in permafrost areas; geochemical element anomalies and endemic diseases prevention and control; physical geographical elements in-situ observation; and geospatial differentiation identification and geographical detectors. The study of physical geography in practice and application-related fields has deepened the understanding of the patterns and processes of terrestrial surface system and bolstered the agricultural development, regional development, rational use of resources, and ecological civilization building in China.

The nature, content, methods, and role of physical geography have developed tremendously in the context of contemporary scientific development and social needs (Cai, 2010). With population growth, social development, and scientific and technological progress in China, the impact of human activities on the natural environment is increasing, and physical geography has been developed and promoted in serving government decision-making and national needs $(\mathrm{Fu}, 2018)$. In summarizing the basic research of physical geography and the living environment in China (Chen et al., 2019), we reviewed the main practices and appli- 
cation fields of physical geography in China over the past 70 years. We have also summarized the most important research progress and achievements with local characteristics, examined the focus and expansion of the practices and application of physical geography. In this way, we strive to initiate ideas for further developing the theoretical practice and application of physical geography to promote the ecological civilization in China.

\section{Research progress in the practice and application of physical geography}

\subsection{Comprehensive physical regionalization serves national land development and utilization}

The comprehensive physical regionalization takes the land surface complex as the primary subject. Its main objectives are to reveal the regional differentiation laws of natural elements, divide regions in hierarchy according to the spatial characteristics and combinations of different elements, systematize the regional complex environment and form a terrestrial system of the land surface. China has a vast territory with varying environments. Therefore the natural territorial system provides scientific basis for resources management and the planning of social and economic development.

2.1.1 Classical comprehensive physical regionalization serves national agricultural production

Under the guidance of the theory of regional differentiation law, the basic research of comprehensive physical regionalization has developed rapidly in China, and the national regionalization scheme has been formulated extensively. In the 1950 s, the country needed to deploy agriculture, forestry, and animal husbandry based on local conditions, and so the study of comprehensive physical regionalization was implemented based on thorough scientific expedition and research of natural conditions and resources throughout the country. Subsequently, a series of regionalizations were produced, such as the outline of the physical regionalization of China (Lin, 1954) and a draft of regionalization of Chinese physical geography (Luo, 1954). In particular, the research team led by Zhu Kezhen and Huang Bingwei completed "The Comprehensive Physical Regionalization of China (Draft)" (Huang, 1959) based on eight professional geographical regionalizationgs such as geomorphology, climate, and vegetation. The scheme aimed at persistently maintaining, enhancing, and maximizing production potential, and providing basis for the layout of national agricultural production as well.

The methodology of this study was followed by later studies. Ren and Yang (1961) yielded innovated insights into regionalization indicators, quantitative analysis, hierarchy units and nomenclature. Hou et al. (1963) constructed a physical regionalization scheme for the development of agriculture, forestry, and animal husbandry. Zhao (1983) pioneered a new bottom-up approach based on landforms and designed a new scheme. The regionalization of Xi et al. (1986) focused on the regional physical characteristics, agricultural status, production potential, and development direction. These achievements have been a vital foundation for relevant sectors, such as agriculture, forestry, and transportation, and have had a profound influence on the entire country. Accordingly, the national agricultural comprehensive regionalization was drawn up (Qiu, 1986). The results of this subject won the 
second prize of the National Natural Sciences Award in 1987.

2.1.2 Eco-geographical regionalization serves national ecosystem construction and environmental protection

In the 1980s-1990s, with the needs of ecological construction and environmental protection in China, the viewpoints, principles, and methods of ecosystems were introduced to physical regionalization which expanded to eco-geographical regionalization. Hou (1988) regionalized China into 20 natural ecological regions, Fu et al. (2001) conducted ecological regionalization focusing on sensitive and fragile regions in China. Zheng et al. (2008) established the eco-geographical region and clarified the differences, relationships, and utilization of physical conditions in each area. They revealed regional differences in land degradation and its remediation in these different areas and applied the results to regional ecological and environmental development. The eco-geographical regional system lays the necessary scientific foundation for improving land production potential, policy analysis of land management, and introduction and promotion of advanced agricultural technology and provides a macro-regional framework for the coordination of environment, resources, and development, as well as the selection and planning of nature reserves (Zheng et al., 2008).

2.1.3 Comprehensive regionalization serves national sustainable socioeconomic development

At the end of the 20th century, Huang Bingwei advocated for the study of the comprehensive regional system and believed that there should be a national system with proper consideration of both natural and socioeconomic aspects to meet the current needs (Huang, 2003). Many scholars have examined the theories, indicators, and methods of comprehensive regionalization research (Wu, 1998; Zheng and Fu, 1999; Ge et al., 2003; Wu and Liu, 2005). In addition, according to the genetic principles of natural elements and the regional characteristics of human activities, the researchers collaborated with those in human geography to evaluate the regional function suitability and complete the major function oriented zoning of China. Optimized, prioritized, restricted and prohibited zones were devised based on the county-level administrative units to boost socioeconomic growth on the premise of ecological construction and environmental protection (Fan, 2015).

\subsubsection{Future risk regionalization serves global changes coping}

Since the end of the 20th century, as global changes have been recognized and valued, the study of comprehensive physical regionalization has been enriched and expanded in the direction of future projections. The understanding of the response of regional systems to future climate change has been deepened and quantified (Wu et al., 2010; Li and Ma, 2012; Cheng et al., 2015; Chan et al., 2016; Yin et al., 2019). Furthermore, several analyses have been performed on the dynamic evolution of previous regional systems. Most studies were based on the mainstream indicators of the regional system and achieved a consistent understanding of the general northward shift of the temperature zones in eastern China (Sha et al., 2002; Zhao et al., 2002; Ye et al., 2003; Wu et al., 2016). Compared with the temperature zones, aridity/humidity regional boundaries are more complex with fluctuations (Yang et al., 2002; $\mathrm{Ma}$ and $\mathrm{Fu}, 2005)$. In particular, there is a large spatial variation from east to west (Chen et al., 2018) and a clear expansion trend in the semi-arid zone (Ma et al., 2019). Owing to the 
combined effect of warming and precipitation changes, the monsoon margins of China have been impacted the most, which indicates that this region is more sensitive to climate change (Huang et al., 2019). The recently completed climate change risk regionalization of China (Wu et al., 2017) and the Belt and Road physical geographical system (Wu et al., 2019), provide a regional framework for coping with climate change and disaster risk prevention.

\subsection{Land use and land cover change research serves the coordinated development of human-land relations in China}

Land is the primary base of human activities. Land use and land cover change (LUCC) reflects the influences on land from changes in human activities, natural factors, and their interactions. LUCC plays a crucial role in global climate change and sustainable development (Cai, 2001; Feddema et al., 2005; Foley et al., 2005; Song et al., 2018). For more than 70 years, in response to the enormous spatiotemporal changes in LUCC brought about by the rapid socioeconomic development in China, geographers have focused on the studies of LUCC and its driving forces that directly support the sustainable development of human-land relations in China.

2.2.1 Investigations and research into land resources provide scientific support for agricultural production

Agricultural development has received widespread attention since the founding of the People's Republic of China. After the formulation of "An Outline of the National Agricultural Development 1956-1967" and the two national scientific planning conferences held in 1956 and 1963, it became evident that serving agriculture was a critical direction for geographical research in China (Zhao et al., 1979). Land resources and mapping are significant foundations for the planning and regionalization of various activities. The most important content of the first part in "An Outline of the National Science and Technology Development Plan 1978-1985" was to compile the 1:1,000,000 national land resource map to aid in the development of the generalized agriculture (i.e., farming, forestry, and animal husbandry) and the rational use of land (Shen and Guo, 1981). The land resource map mainly reflects the production potential of farming, forestry, animal husbandry, and side-line occupations, including land suitability and limitations as well as the basic land-use status, and classifies the potential or quality of the land (Shi, 1979).

Land use classification and mapping picture determinacy of present land use status and value of land use. $\mathrm{Wu}$ (1979) proposed a classification system and expression method for the 1:1,000,000 land use map and discussed the land use structure in China, which became an important basis for the subsequent land use classification of the State Land Administration. In the process of land use study, land quality has also received attention and has been studied progressively ( $\mathrm{Su}, 1981$; Liu 1983; Fu et al., 1997), which provides a scientific basis for the layout of agricultural production and the planning of socioeconomic development.

2.2.2 Land use and land cover change and its ecological effects

In 1978, the reform and opening-up policy in China, particularly the household contract responsibility system implemented in rural areas, greatly released the rural labor force. In 1949, China's urbanization rate was only approximately $10 \%$, whereas it was close to $60 \%$ in 2018. China has undergone the largest urban-rural population migration in history, which 
has brought about dramatic changes in LUCC. The Chinese LUCC database based on a series of remote sensing image analysis techniques has mapped the characteristics of land use changes in the country (Liu et al., 2002; Liu et al., 2018) and has provided basic data for the study of human-land relations.

The expansion of construction land is the most prominent feature of land use changes in China (Liu et al., 2018). Construction land expansion is often located in densely populated areas and occupies high-quality farmland. Furthermore, it has been difficult to restore grain cultivation in a considerable part of the area. Therefore, the change in construction land has become a focus of scholars and government departments (Cui and $\mathrm{Wu}, 1990$; Ye and $\mathrm{Li}$, 1999), giving rise to the subsequent "red-line policy of farmland protection" and the policy of "Dynamic Balance of Total Farmland" formulated by the state (Xu et al., 2005; Zhao et al., 2011).

Due to the massive out-migration, the abandonment and conversion of farmland have become the focus of the government and scholars (Feng et al., 2003). Before the 1980s, Chinese farmers converted large tracts of forests and grassland into farmland, mostly on steep slopes, thus causing serious land degradation (Feng et al., 2005). With the large-scale urban-rural population migration, land use has been transformed. The area of farmland, which represents considerable human interference, has shifted from expansion to contraction, resulting in the large-scale abandonment of farmland in mountainous areas ( $\mathrm{Li}$ and Zhao, 2011).

The conversion of farmland and the implementation of various national ecological construction measures have curbed the national land degradation, and the overall ecological situation has begun to improve. For instance, with the construction of nature reserves on the Qinghai-Tibet Plateau and the implementation of ecological engineering and planning, the area of grasslands and wetlands have increased, the area of bare lands has decreased significantly, and the ecological functions of most nature reserves have been strengthened (Shao et al., 2010; Zhang et al., 2014; Qi et al., 2016; Zhang et al., 2019). The ecological improvement in China has made a significant contribution to global greening and increased forest cover. In particular, the leaf area of new vegetation in China accounted for approximately 1/4 of the global increase between 2000 and 2017 (Chen et al., 2019).

\subsection{Natural disaster processes and risk assessment studies serve national needs for disaster reduction and relief}

With the diversity in human living environments (Chen et al., 2019), China has become one of the most serious countries suffering natural disasters worldwide. Over the past 70 years, different disciplines have conducted in-depth discussions on natural disasters in China, especially on hazards in China. Physical geography has expanded from the study of hazards and processes of major natural disasters (such as debris flows) to the study of the prevention and relief of natural disasters. The index system of disaster risk assessment has been continuously optimized and has shifted from disaster assessment to comprehensive risk studies that measure hazards, exposure, vulnerability, and reduction capacity. The study of disaster risk in China in the 1980s focused on the disaster possibility and hazard risk. With the increased awareness of the risk, the need for socioeconomic development, and the promotion of the International Decade for Natural Disaster Reduction in the 1990s, disaster risk re- 
search has developed rapidly in China. In particular, with the improvement in the data acquisition capabilities, disaster assessment indicators have been enriched from early vulnerability (Chen et al., 1999) to trigger factors, land surface conditions, and regional socioeconomic conditions (Zhou et al., 2000), to the probability of hazards and disaster losses (Shi, 2005), and to comprehensive disaster risk, disaster change, regional socioeconomic growth, and regional disaster resilience (Zhang and $\mathrm{Li}, 2007$ ). The improvement in disaster risk assessment indicators has greatly enhanced the comprehensiveness and scientificity of risk assessment in China. The research on natural disaster risks has developed into an emerging discipline mostly carried out by physical geographers. Natural disasters involve multi-disciplinary research. The present study summarizes the contribution and progress of physical geography in the study and prevention of natural disasters.

2.3.1 A relatively systematic knowledge system of debris flow discipline has been preliminarily formed, and technologies of disaster reduction has produced good results in disaster reduction at home and abroad

Debris flow is a sudden natural disaster unique to mountainous areas, which seriously threatens the safety of mountainous towns, hydropower projects, and main transportation lines, resulting in hundreds of deaths and huge economic losses every year. In the 1950s, China conducted systematic research on debris flow mitigation, and its development could be divided into the following three stages. Before 1978, using field investigation, in-situ observation, simple field experiments, and routine instrument analysis, the distribution patterns, hazard status, and activity characteristics of debris flow in China were preliminarily identified. The debris flow was systematically classified, and the rheological model of debris flow was presented. New technologies such as the Dongchuan debris flow drainage trough and box filling sand barrage were developed (Tang et al., 2000). From 1978 to 2000, the Dongchuan Debris Flow Observation Station was built into a semi-automated observation station. The largest indoor debris flow dynamics simulation device in Asia was installed, which supported the development of debris flow research from a descriptive discipline to an experimental discipline. A series of debris flow testing devices, such as the NSZ10 debris flow viscometer, were developed to observe and catalogue semi-automated debris flow for the first time worldwide (Zhong et al., 1998). Based on granular gravity flow, a mechanical model of debris flow (Zhou, 1995) was established, the catastrophe model of viscous debris flow initiation was devised (Cui, 1992), and the monitoring and early warning method and technology for debris flow were established. A complete set of prevention and control techniques were developed, and systematic breakthroughs were made in the regional law, formation mechanisms, movement laws, mechanics, and prevention techniques of debris flow, thereby establishing a preliminary discipline system (Zhou et al., 1991; Tang et al., 2000). Since 2000, based on a multidisciplinary crossover, the automated observation level of debris flow in Dongchuan has been raised further, which makes the Dongchuan Station one of the first national field observation and research stations. The Tibet Bomi Debris Flow Observation and Research Station has also been established to meet the needs of debris flow research in ice- and snow-covered areas. A scale-up model for cascading failures and a risk assessment method based on dynamic processes (Cui et al., 2013a; 2013b) were set up to construct the world's first numerical simulation platform for debris flow founded on forward modeling. The theoretical and technical methods of post-earthquake mountain disasters, 
from the regional laws and dynamic processes to the risk assessment system, were devised (Cui et al., 2011). The key technical system for the prevention and control of large-scale debris flow was established and successfully applied in a typical debris flow control project in the Wenchuan earthquake area (Chen et al., 2015).

After more than 70 years of continuous studies, debris flow research in China has formed a discipline with modern observations, experimental and testing methods, a systematic and complete theory, and an advanced disaster reduction technology system, and is in a leading position worldwide. Apart from scientific research, debris flow theory and disaster reduction technologies have been applied to disaster prevention and control in China and Third World countries, achieving good results in disaster reduction. Typical comprehensive debris flow control projects, such as Heisha River, Hunshuigou, Daqiao River, Jinchuan County, Xichang Satellite Launch Center, Chengdu-Kunming Railway, Sichuan-Tibet Highway, and Jiuzhaigou (Zhou et al., 1991; Cui et al., 2005) have been completed successively. The urban debris flow control model, farmland debris flow control model, road debris flow control model, and scenic spot debris flow control model have been formed to support disaster reduction, engineering construction, and landscape ecological protection in mountainous areas. The recently completed risk assessment of Sichuan-Tibet Railway has provided scientific and technical support for the pre-feasibility study of railway engineering. Disaster reduction techniques have also been used for disaster reduction in the massive Venezuelan mudslide, the Nepal earthquake, and the China-Pakistan Economic Corridor (Chen et al., 2017), producing a positive international influence.

2.3.2 Shift in researches of disaster risk from single-hazard to comprehensive risks from multi-hazard gradually

In the 1990s, the concept of multi-hazards was introduced in the world, and the concept of disaster risk assessment was constantly improved. The study of disaster risk assessment in China began to focus on multi-hazard comprehensive risks. After the Wenchuan earthquake in 2008, the study of seismic geological disaster chains based on the theory of regional disaster systems has received attention (Shi et al., 2009), and disaster risk assessment has increased the identification of risk from geological disasters. Multi-hazard risk assessment has introduced advanced technical methods, and disaster chain risk assessment techniques based on the transmission probability coefficient have been developed (Yue et al., 2018). In recent years, the comprehensive research methodology perspective of physical geography has been introduced to disaster risk research. The study of multi-hazards disasters in China has become more systematic and quantitative to be a research system with explicit terminology. Moreover, greater focus has been on the damage severity caused by multi-hazard disasters. Shi and Lv (2014) clarified three categories, including disaster group, disaster chain, and disaster encounters, in accordance with the complexity of disaster systems and the relationships between disasters. The national comprehensive disaster risk map (Ge et al., 2008; Fang et al., 2011) demonstrates the regional differences in comprehensive risk governance in China and provides a more specific scientific basis for decision-making for regional disaster prevention and mitigation.

2.3.3 Development of an integrated disaster risk assessment system for climate change

Based on the uniformity of the global change scenario analysis and disaster risk concepts, 
disaster risk of climate change has become a substantial area of research. In 2015, China released a disaster risk assessment report on climate change (Qin et al., 2015). In the early 21 st century, research began to value climate change risk assessment, and it was emphasized that targeted risk management actions were an effective way to deal with climate change (Liu et al., 2005). Research frameworks and concepts related to climate change risk as well as important characteristics such as vulnerability have been presented (Wu et al., 2011), and hydrometeorological disaster risks have been quantitatively assessed (Wu et al., 2014). Su et al. (2018) indicated that if the warming difference was $0.5{ }^{\circ} \mathrm{C}$, the economic loss arising from drought disasters in China would be 100 billion yuan.

Recently, China has gradually formed a comprehensive climate change risk assessment system. Using the concept of 'consilience' in integrated risk governance of a socioecological system, fundamental principles, synergistic efficacy, and operational means, the scientific connotations and models of "consilience" were systematically studied. The deficiencies of the concepts of vulnerability, resilience, and adaptation in the interpretation of comprehensive risk governance in disaster systems have been overcome (Shi et al., 2014). In addition, based on the spatial distribution of climate change sensitivity, the degree of disaster risk due to extreme events has been quantitatively predicted in combination with the severity of extreme events, such as high temperatures and heat waves, drought, and extreme precipitation, presenting a pattern of regional differences in disasters in the context of future climate change (Wu et al., 2017).

2.3.4 Disaster risk assessment supports the national management of disaster prevention and reduction

In natural disaster risk research, the state has funded several major scientific research projects. Numerous original achievements have been made in the theories and methods of regional disaster systems, comprehensive assessment technology of losses and risks in major natural disasters, compilation of the atlas of natural disasters in China (Shi, 2011), major natural disaster responses and agricultural natural disaster insurance techniques. A modeled, mapped, real-time, standardized, and integrated comprehensive disaster risk reduction technology system has been created to resolve scientific and technological problems in disaster assessment, such as the lack of systematic statistical guarantee and timeliness, and poor accuracy. The theory of a regional disaster system has been proposed for the first time worldwide, and a comprehensive risk assessment model has been established. The System of Statistics on Losses in Major Natural Disasters has been firstly developed and applied nationwide. The national natural disasters regionalization and agricultural risk and insurance regionalization have also been set up for the first time in China. A national technical support system for major natural disaster assessment operations has been set up. These researches have supported the comprehensive loss assessment of major natural disasters, such as earthquakes in Wenchuan, Yushu, Lushan, Ludian, Jiuzhaigou, Haiti, Japan, and Nepal, Zhouqu mountain floods and debris flows, and freezing rain and snow in south China in the past decade. The assessment results have been adopted by the country, which has significantly improved the national scientific and technological capacity for comprehensive disaster reduction and risk governance as well as the ability to respond to major natural disasters. This series of achievements won the second prize of National Science and Technology Progress 
Award in 2018.

\subsection{Research on desertification process and development of prevention and control technology}

Desertification is one of the most serious environmental-economic-social problems worldwide (Reynolds et al., 2007). In the early stages, desertification was only understood as the degradation of land productivity caused by desert expansion, dune invasion, and drought (Dregne, 2002). The United Nations Conference on Desertification held in 1977 established an official definition of desertification for the first time. In 1992, the United Nations Conference on Environment and Development defined desertification as "land degradation in arid, semi-arid, and dry sub-humid areas caused by climate change and human activities." This concept is used to guide countries to conduct desertification research. Unique climatic spatial differences, diverse natural and geographical conditions, and a long history of human activities in China (Zheng et al., 2008; Chen et al., 2019) have led to the severity and diversity of desertification in China. According to the results of the fifth national monitoring, as of 2014, the desertified land area reached 2.6116 million $\mathrm{km}^{2}$, accounting for $27.20 \%$ of the national territory (SFA, 2015). Desertified land results from rocky desertification in southwest China, wind and sand disasters and desertification in arid and semi-arid areas in northwest China, and soil and water loss in the eastern monsoon areas. Physical geographers have performed fruitful basic and applied research in these aspects, which have made substantial contributions to the development of the country.

2.4.1 Research on the process of rocky desertification and its prevention provides scientific support for the sustainable development of karst regions in southwest China

Rocky desertification is the process of transforming karst areas covered with vegetation and soil into rocky bare landscape (Yuan, 1997). Karst covers $540,000 \mathrm{~km}^{2}$ in southwest China (Bai et al., 2009). This region is one of the three karst-concentrated regions worldwide and is considered to be the "world's largest continuous belt of karst zone (Sweeting, 1993)." This region is inhabited by over 100 million people, including 31 ethnic minorities with a population of over 40 million. Rock desertification often occurs in the areas of old revolutionary base, minority nationality, remote border, and poverty. The cycle of desertification and poverty, which is intertwined and mutually reinforcing, has become a key bottleneck for the sustainable economic and social development of karst regions. Breaking this vicious cycle is a worldwide problem (Dyson-Hudson, 1983; Cai, 1996; Cai, 1999).

Since the founding of the People's Republic of China in 1949, especially in the 21 st century, the state has implemented a series of ecological construction projects, carried out rocky desertification control, and made remarkable achievements, in which scientific and technological research and development have played an important supporting role. The study of karst and rocky desertification in China began with geomorphology and hydrogeology, and then from the perspective of ecology and "human-land relations," achieving a series of research results. In terms of pattern research, the concept and definition of rocky desertification were presented, the classification standard of rocky desertification was established, and the spatial distribution of rocky desertification was defined, thus providing a scientific basis for regional control. By the end of 2011, the total area of rocky desertified land in China was 
about 120,000 km², distributed mostly in Guizhou, Guangxi, Yunnan, Chongqing, Hubei, Hunan, Sichuan, and Guangdong provinces (or municipalities/autonomous regions). In terms of process research, the causes and driving forces of rocky desertification were summarized as natural factors and artificial factors. Natural factors include the geological background of carbonate rocks, broken mountainous landforms, high-temperature and rainy climatic conditions, scarce and unstable soil resources, and simple and fragile biological communities. Human-made factors include overloaded population, unreasonable land use, backward economic development and industrial structure (Wang, 2002; Cai, 2015), and management policy failures (Zhang, 2016). In the process research, attention has also been paid to the ecological and social effects of rocky desertification. The influence mechanisms of rocky desertification and land use changes on groundwater quality (Jia and Yuan, 2003; Zhang and Yuan, 2004), soil quality (Li and Xie, 2001), and soil erosion (Wan et al., 2003) were explored, and the relations between rocky desertification and local economy (Xu and Cai, 2006) and poverty (Xu et al., 2006) were examined.

In the research and development of comprehensive management technologies, according to different types of karst environments, small basins have been used as the control unit, and the comprehensive development and governance of multi-disciplinary and multi-technology integration have been carried out to establish a model governance pilot zone. Technical problems have been addressed in the aspects of karst groundwater exploration, water resource regulation and efficient use, optimal utilization and control of soil moisture and nutrients as well as leakage control, ecological restoration and optimal allocation of degraded vegetation communities, and characteristic products and compound management in agriculture. Therefore, a comprehensive technical integrating "water-soil-biology-human" for rocky desertification control was established. Through the projects for controlling of rocky desertification, the area of karst rocky desertification in southwest China decreased by $30,000 \mathrm{~km}^{2}$ from 2005 to 2016 (Tong et al., 2018). Nature published an article that affirmed the effectiveness of rocky desertification control in China (Macias-Fauria, 2018). Regarding comprehensive research and management at multiple spatial scales, it has been found that the patterns, processes, driving forces, effects, and comprehensive management of rocky desertification show significant spatial scale characteristics. Geographers have conducted multi-scale comprehensive research to reflect system holistic characteristics, predict future scenarios, formulate corresponding countermeasures, and serve the sustainable development of southwest China.

2.4.2 Research on desertification and soil wind erosion serves the prevention and control of desertification in northwest China

The study of desertification in China began with the theory of "renovation of ancient sand" (turn the sand in place) presented by Yan Qinshang (1954). Subsequently, scholars gradually realized that sand-desertification was a part of desertification (Zhu, 1994) and defined that "desertification is an environmental change process similar to the desert landscape in the original non-desert area, which is mainly marked by wind-blown sand activities (Wu, 2003)." Sandy desertification is one of the primary types of desertification in China. In the vast arid, semi-arid, and semi-humid areas in northwest China (Gansu, Xinjiang, western Inner Mongolia, and western Qinghai) and the eastern monsoon fringe (central and eastern Inner Mongolia, Shaanxi, Shanxi, and northern Hebei) (Zheng et al., 2015; Chen et al., 
2019), there are typical native deserts and desertified lands. As of 2014, there were 1.7212 million $\mathrm{km}^{2}$ of desertified and quicksand lands, which accounted for $17.93 \%$ of the national land area (SFA, 2015). The actual area of desertification in northern China was $375,900 \mathrm{~km}^{2}$ in 2010 (Wang et al., 2011), accounting for approximately $14.39 \%$ of the total area of desertified land in China.

The dynamic mechanism of land desertification is different at different time scales, in which wind-blown sand activity is one of the important driving forces of desertification. Current research shows that the wind-blown sand activity in desertified areas in China has changed significantly in the past 50 years. It was the strongest in the 1970s but at low ebb between 1980 and 2000, with an intensity of approximately $20 \%-50 \%$ of that in the $1970 \mathrm{~s}$, or even lower. After 2000, the weakening trend of wind-blown sand activity was more obvious, with the reversal of desertification in the sandy lands of Hulun Buir, Horqin, and Hunshandake. In the Ordos region, the wind-blown sand activity drastically led to the rapid development of desertification before the 1980s. However, after the 1990s, the wind-blown sand activity weakened, desertification reversed, and the strength of wind-blown sand activity had a decisive influence on desertification (Wang et al., 2008). From the end of the 1950s to 2015 , the area of desertified land in China increased from approximately $300,000 \mathrm{~km}^{2}$ to $400,000 \mathrm{~km}^{2}$, reaching its peak in 2000 , and then decreased annually. Since the 21 st century, the desertified area in China has decreased by about $16,500 \mathrm{~km}^{2}$ (Figure 1) (Wang et al., 2011). With regard to the causes of desertification in China over the past 70 years, Zhu Zhenda proposed that desertification was mainly caused by human activities (Zhu, 1979), based on which many scholars have conducted relevant research (Wang et al., 2015). Nevertheless, some studies have found that the impact of human activities on the process of desertification has been limited to specific areas and scattered over the past 50 years (Cao, 2008). Human activities in desertified areas in China have been increasing. However, the reversal of desertification has occurred in most of the desertified areas since the 1980s (Wang et al., 2009) and has shown an overall regional reversal (Zhu et al., 2016). Current research also shows that in the oasis area to the west of Helan Mountain, the process of desertification is also closely related to the change in water resources (Wang et al., 2008). Therefore, climate change may be the dominant factor in the overall change of desertification in northern China, and human activities may affect spatial differences in desertification change.
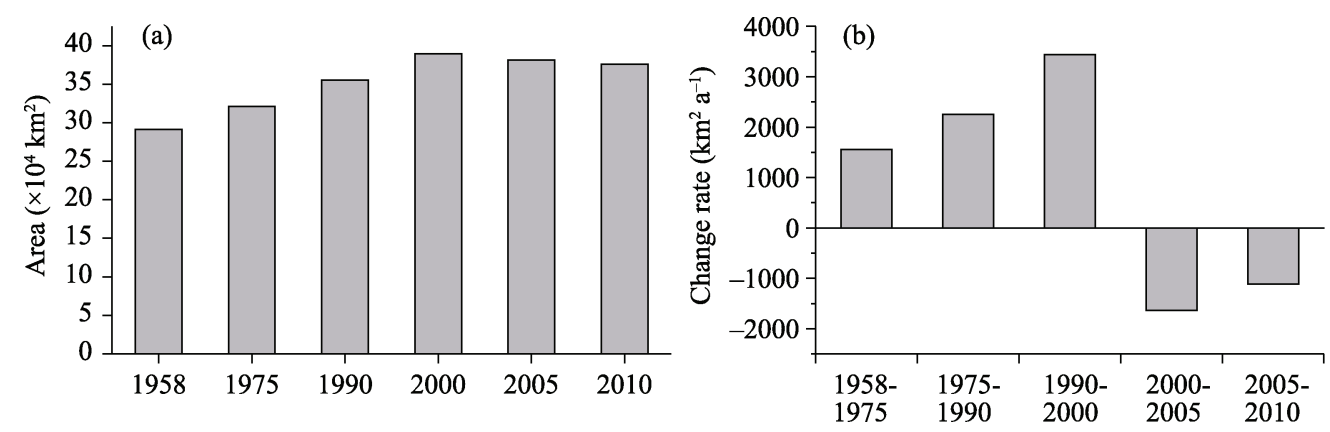

Figure 1 Area (a) and variability (b) of sand-desertification in China from the late 1950s to 2010 (after Wang et al., 2011) 
Soil wind erosion is the process by which wind forces cause topsoil material to be separated from its original spatial location (Zou et al., 2014), and is the primary link leading to the land desertification (Shi et al., 2004), various blown sand disasters (Zhang et al., 2010; Zou et al., 2018), as well as mineral dust emission and atmospheric environmental pollution (Borbély et al., 2004; Goudie, 2014). Thus, the United Nations Environment Program and over 100 national governments have attached great importance to soil wind erosion (UNCCD, 1994). An important effect of soil wind erosion is the fine particles of topsoils which are blown off the surface by wind, forming desertified land locally. Since the Han Dynasty, many emigrants have developed the natural oasis in arid areas, forming an agricultural oasis mainly based on farmland, which has led to large-scale desertification of the oasis in arid areas. In Minqin of the Hexi Corridor and Juyanhai Oasis in the lower reaches of the Heihe River, unreasonable human development and utilization resulted in subsequent abandonment and desertification, which is a typical example of anthropogenic desertification (Jie and Chen, 2008; Zhao et al., 2015; Xie et al., 2009). In the eastern monsoon fringe area, the strong summer winds over the last 2,000 years have resulted in abundant precipitation at the monsoon margins. Large-scale immigrant groups have reclaimed grasslands as farmland and increased immigration towns and villages. However, due to the dry climate overall, large-scale desertification has occurred, resulting in frequent sandstorms, abandoned farmland, and the natural restoration of desertified land. During the subsequent monsoon recession, despite reduced rainfall, ancient cities and farmland were abandoned due to population reduction. The reclaimed land naturally returned to grassland, which led to a reduction in sandstorm activity under the background of the summer monsoon recession. This resulted in a combination of rainy periods-high intensity of secondary sandstorms, and periods of low rainfall-low sandstorms (Figure 2). This indicated that from 2,000 years ago on, in the marginal monsoon areas, the impact of human activities on the surface exceeded that of natural processes (Chen et al., 2020), which became a typical example of desertification caused by unreasonable human activities.

(a)

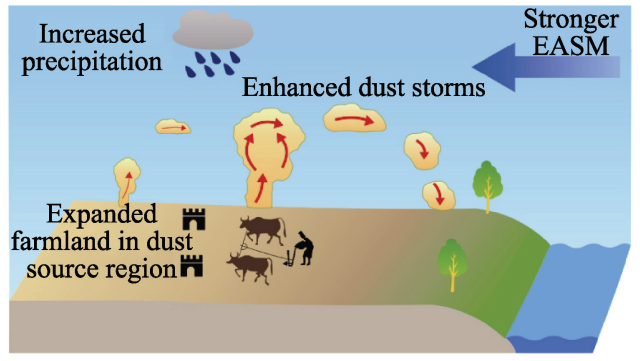

(b)

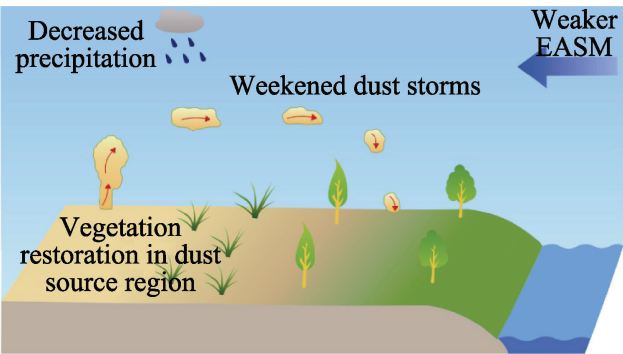

Figure 2 Schematic of the response of sand and sandstorms to human activities and changes in the Asian monsoon over the past 2000 years in the monsoon fringes of eastern China (after Chen et al., 2020). (a) The period of strong summer monsoon-strong human activity-desertification expansion-strong sandstorm; (b) The period of weak summer monsoon-weak human activity-vegetation restoration-weak sandstorm

The sand control team of the Chinese Academy of Sciences began to examine desertification governance, blown wind and sand disasters, and the prevention and control of soil wind erosion in China in 1959. The team was formed of approximately 800 scientific and technical experts from domestic research institutes, colleges and universities, and production de- 
partments, to perform large-scale comprehensive investigations on major deserts, Gobi, and oases in China. Between 1959 and 1965, six comprehensive sand-desertification control experimental stations and 20 sand-desertification control central stations were established. The experimental studies were conducted to prevent farmland and railways from blown sand damages, and to control soil wind erosion, opening a new chapter in the comprehensive study of deserts and their governance (Wu, 2009a; Wu, 2009b). Several achievements have been made (Geng, 1959; Liu, 1960; Wu, 1962; Wu and Lin, 1965), and a large number of young scientific and technical experts have been trained, which has laid a solid foundation for the theoretical and technical research and engineering layout of the subsequent blown sand disasters, desertification, and soil wind erosion control. From 1966 to 1977, scientists and technicians overcame difficulties and insisted on conducting technical research on the prevention and control of wind erosion and desertification of farmland in multiple oases. Therefore, it was proposed that they implemented sand-sealing and grass-fed measures on the periphery of the oasis to protect vegetation, establish belt-shaped and sheet-shaped shelter forests on the edge of the oasis, and create wider sparse structure forest belt near the oasis. The combination of long-living and fast-growing, tall and low tree species were adopted, and techniques such as narrow forest belts and small forest nets were used in the oasis (Zhu, 1979). These techniques remain widely used today. The period from 1978 to 2000 saw great developments in the study of soil wind erosion theory and technology in China. The soil wind erosion theory and technology advanced towards quantification (He et al., 1986; Liu et al., 1992; Zou et al., 1994; Dong, 1998; Huang et al., 2001; Wang et al., 2001; Yan et al., 2001), which provides a reliable theoretical basis and technical support for the implementation of national prevention and control projects, such as the "Three-Norths Shelterbelt Project." In the 21 st century, owing to the promotion of major regional projects such as the national "Grain for Green Project" (Phase II), the research results on desertification and soil wind erosion in the past 50 years $(\mathrm{Ci}, 2005$; Wu, 2003; 2009b) have been summarized. Further, new advances have also been made in the theory and technology of wind erosion prevention, soil wind erosion prediction models, and calculation methods for directional transmission of wind erosion objects (Zhang et al., 2004; Wu et al., 2011; Gao et al., 2012; Mei, 2013; Wang et al., 2015; Fang et al., 2018; Yang et al., 2018), which adapted to the later benefit assessment of major projects and future technology needs. The further developed soil wind erosion model, which contains three types of land use of farmland, sandy land (desert), and grass (shrub) land has become the first quantitative model officially used to calculate the soil wind erosion modulus in China (LOFNWRS, 2010), which has positively contributed to accurately understand the nationwide dynamic changes in the area, distribution, and intensity of soil wind erosion, and in the factors influencing soil wind erosion.

2.4.3 Research on soil and water conservation provides theoretical support for the sustainable development of agriculture and ecology in the eastern monsoon region

Soil and water loss are significant environmental problems that constrain human survival and sustainable development in society. The study of modern soil and water loss in China began with the observation of soil erosion and runoff plots in the 1940s and has since been conducted in the Tianshui area of the Yellow River Basin, focusing on vegetation, protective dikes, and terraces for soil and water conservation (Liu, 1953; Wang, 2001). Since 1949, the Ministry of Science and Technology, the Ministry of Water Resources, and the Chinese 
Academy of Sciences have successively set up field observation and test stations in key areas of soil and water loss across the country to carry out field positioning observation and scientific research. With the continuous improvement in monitoring indicators and devices, a perfect nationwide monitoring network has been built. Currently, 784 monitoring sites and 75,846 field investigation units have been established in China, forming an integrated monitoring network (Zhao and Ma, 2016).

With the deepening of basic research on soil and water conservation in China, Chinese geographers have made a series of achievements in basic research on the mechanism of soil and water loss (Zhu, 1989; Jiang, 1997; Zhao et al., 2002; Tang, 2004), slope soil erosion model and prediction (Cai et al., 1998; Liu et al., 2001; Tang, 2004), vegetation erosion reduction mechanisms (Li et al., 1991; Tang, 2004; Yu et al., 2006), and benefit evaluation of soil and water conservation (Jiang, 1997; Cai et al., 1998; Lu, 1997; Tang, 2004; Fu, 2016; Yu et al., 2016; Liu et al., 2017). As a result, a disciplinary system for soil and water conservation with Chi nese characteristics has been designed (Guan, 2002).

Regarding applied research, China has made a series of important achievements in soil erosion classification, regionalization, and mapping. In the $1960 \mathrm{~s}$, a map of soil erosion types in China was compiled for the first time. After nearly 70 years of achievements, some significant understandings regarding the differentiation patterns and regional prevention and control of soil erosion in China have taken shape (Xin and Jiang, 1982; Tang, 2004; Zhou et al., 2009; Ning et al., 2015; Wang et al., 2016; Yang et al., 2017). On this basis, combined with regional economic, cultural, and social differentiation patterns, the compilation of the "Regionalization of Soil and Water Conservation in China" was ultimately competed. China is divided into eight primary soil and water conservation regions, such as the black soil region in the northeast, the sandstorm region in the north, the mountainous region in the north, the Loess Plateau in the northwest, the red soil region in the south, the purple soil region in the southwest, the karst region in the southwest, and the Tibetan Plateau, as well as 41 secondary regions and 117 tertiary regions. The regionalization provides important technical support for regionalization, planning, and implementation plan formulation of soil and water conservation at all levels in China. In addition, in long-term practice, a comprehensive management model and technical system with small basins as units have taken shape in China (Gong and Jiang, 1979; Lu, 1997; Li, 1999). In the Loess Plateau where soil and water loss is most serious, a 28-character land improvement strategy with the characteristics of the Loess Plateau (Zhu, 2006) and an eco-agricultural technology system for soil and water conservation (Lu, 1997; Li, 1999) have been created. Through continuous efforts, China has made huge achievements in soil and water conservation. According to China Soil and Water Loss Monitoring Bulletin 2018 (http://www.mwr.gov.cn), the area of soil and water loss nationwide in 2018 was $2,736,900 \mathrm{~km}^{2}$, accounting for $28.60 \%$ of the national land area (excluding Hong Kong, Macao, and Taiwan), which was reduced by $212,300 \mathrm{~km}^{2}(7.20 \%)$ compared with 2011. The hydraulic erosion area was 1.1509 million $\mathrm{km}^{2}$, accounting for $42 \%$ of the total soil erosion area and $12 \%$ of the national land area. The wind erosion area was 1.586 million $\mathrm{km}^{2}$, accounting for $58 \%$ of the total soil erosion area and $16.60 \%$ of the land area. At present, the basic characteristics of soil and water loss across the country are as follows: first, the area of soil and water loss continues to decrease; second, soil and water loss is primarily moderate and mild, and the intensity is decreasing appreciably; third, the 
reduction in hydraulic erosion is large, whereas the reduction of wind erosion is small; and fourth, the reduction is large in the eastern region, whereas the absolute reduction is large in the western region.

The concept of soil erosion control in China has been changing with the needs of the country. In the 1950s, planting trees and grasses was the main measure to reduce serious soil and water loss. In the 1960s-1980s, priority was given to the construction of basic farmland to resolve the problem of low agricultural productivity. After the 1980s, on the basis of experience gained before systematic review, the comprehensive governance policy for soil and water loss with the overall planning of large and small basins as units was designed to improve the ecological protection and economic development of the basins. After the 2010s, China began to carry out the construction of "Life Community of Mountains, Rivers, Forests, Fields, Lakes, and Grass," aimed at improving the synergistic development of ecology, economy, and society. In these studies, geographers have played a positive role, been awarded national scientific and technological progress awards, and made contributions to the sustainable development of agriculture and ecology.

\subsubsection{Water resources regulation and ecological barrier construction in the Tarim Basin}

The Tarim River is the largest inland river in China originating in the Karakoram Mountains and flows into the Tarim Basin in Xinjiang, with many tributaries under natural conditions. The tributaries swing naturally after flowing into the basin, and there are many lakes and luxuriant natural forests and grass along the bank. Since the 1950s, to satisfy the needs of the rapid increase of population and grain production in the basin, the soil in the middle reaches has been rated and its prospects for improvement and utilization were investigated (BWSD, 1958). The hydrogeological conditions, wasteland reclamation, saline soil improvement, and other problems in the riparian areas have been studied (Chen et al., 1959). Large-scale agricultural reclamation has been carried out, which has objectively upset the already fragile balance of the natural ecosystem, resulting in serious land desertification and salinization problems. Water resource problems are prominent, the impact is increasing, and ecological and environmental problems are pronounced (Deng, 2009). In the past 70 years, the Tarim River Basin has undergone the following four periods: disorderly development of resources, deterioration of the ecological environment, comprehensive planning and governance, and initial governance results, of which physiographic research has played a vital role in planning and development.

In the 1950s-1960s, large-scale farming reduced the inflow from the upper reaches of the Tarim River by nearly $50 \%$, and the water loss from Alar to Kara was nearly $80 \%$. All the water downstream of Kara entered the Daxi Haizi Reservoir, and the rivers downstream of the Daxi Haizi Reservoir were cut off (Fan, 1979). In the late 1970s, experts and scholars paid attention to the changes and causes of the ecological environment of the Tarim River Basin, and paid attention to the relationship between the development and utilization of resources and the ecological environment. Major comprehensive scientific research projects such as the comprehensive investigation of the Tarim River Basin and the comprehensive remote sensing investigation were carried out successively (Tian, 1982; Liu, 1989). In the 1980s, the Xinjiang Institute of Ecology and Geography (XIEG) of the Chinese Academy of Sciences (CAS), the Xinjiang Institute of Geography, and other research institutions conducted studies on the characteristics and changing processes of desertification, as well as the 
characteristics of major vegetation communities in the Tarim River Basin (Ling et al., 1985; Li et al., 1990). In addition, evaporation experimental stations were established in the upper reaches of the Tarim River. In the 1990s, the ecological environment of the Tarim River Basin deteriorated. Geographers facilitated the completion of the Main Stream Contour Planning of the Tarim River and the Basin Planning for the Main Stream of the Tarim River. The Tarim River Basin was also included in the National Plan for Major River Management.

As western China is continuing to develop, increasing attention is being paid to the ecological environmental problems of the Tarim River Basin. Progress has been made in the studies on the ecological and environmental effects of the Tarim River management project, emergency water transfer, and water regulation, which support the recent comprehensive management of the Tarim River Basin (Cong et al., 2003; Chen et al., 2004). The CAS launched an ecological effect evaluation of the recent comprehensive treatment project in the Tarim River Basin. The results showed that from 2001 to 2013, the comprehensive treatment project of the Tarim River Basin achieved the objective of water transfer downstream and ended the nearly 30 -year history of downstream water cutoff. The natural environment of the downstream green corridor was improved, the groundwater level was significantly elevated, the natural vegetation was gradually restored, and the trend of land desertification was initially curbed. Overall, favorable ecological, economic, and social benefits were achieved (Deng et al., 2016; Chen et al., 2017). In addition, geographers also presented sustainable ecological construction and management models suitable for different regions and site conditions. These models provide scientific guidance and can serve as practical examples for the construction of ecological barriers and the development of ecological industries on the southern fringes of the Tarim Basin (Xue et al., 2017).

Based on the Tarim Desert Highway Shelterbelt ecological construction project, systematic studies were conducted on the biotechnology (Di et al., 2005), water and salt transport in soil (Li et al., 2005; Zhou et al., 2006), and site conditions (Li et al., 2008). The plant species suitable for the ecological construction of the Tarim Desert Highway Shelterbelt were determined, and the technical problems, such as irrigation and growing seedlings using high salinity water in shifting desert regions, were solved. The index system of site type division in the unsuitable afforestation areas of the shifting desert regions was established. Site type areas and site types were classified. The plant allocation mode and forest belt structure for sand control were presented, and the technical solution of afforestation by high salinity water irrigation in the shifting desert was established (Xu et al., 2006), which made great contributions to the ecological engineering construction of the Tarim Desert Highway Shelterbelt running through the Taklamakan Desert. The Tarim Desert Highway Shelterbelt ecological project set a precedent for the prevention and control of wind-blown sand in the world and attracted wide attention locally and abroad. "The First Green Corridor Crossing the Taklimakan Desert" was rated as "The Top Ten Science and Technology Progress News Items of China in 2006" by the CAS and the Chinese Academy of Engineering. The project was also rated as "The Top Ten National Environmental Friendly Project" in 2008, and the Tarim Desert Highway was rated as "The Top Ten Most Beautiful Highway in China" in 2014. "Development and Application of Ecological Construction Technology of the Tarim Desert Highway Shelterbelt" has won the second prize of the National Science and Tech- 
nology Progress Award in 2008.

\subsection{Comprehensive geographical study promotes transformation of low to middle yield fields in the sandy and saline-alkali land of the Huang-Huai-Hai Plain, achieving favorable results}

The Huang-Huai-Hai Plain, also known as the North China Plain, refers to the alluvial plain in the lower reaches of the Yellow River, Huaihe River, and Haihe River, including Beijing, Tianjin, Hebei, Shandong, Henan, Jiangsu, and Anhui. With a total area of about 350,000 $\mathrm{km}^{2}$, it is the largest alluvial plain and an important grain producing area in China. The cultivated area is $180,000 \mathrm{~km}^{2}$. The Huang-Huai-Hai Plain is one of the most important agricultural areas in China, which has abundant sunlight, rich thermal resources, a flat terrain, thick soil layers and a long history of cultivation. However, the Huang-Huai-Hai Plain has long been threatened by natural disasters such as floods, droughts, salinization, and sandstorms, restraining agricultural productivity. Since the founding of the People's Republic of China, a large-scale treatment of $54,700 \mathrm{~km}^{2}$ degraded land in the Huang-Huai-Hai-Plain was conducted. Focusing on soil improvement and water control, the treatment has achieved remarkable results. Since the 1950s, the CAS has successively established several experimental stations in the Huang-Huai-Hai region, including the Yucheng Comprehensive Experimental Station of the Institute of Geography; the Luancheng Eco-Agricultural Experimental Station and Nanpi Eco-Agricultural Experimental Station of the Shijiazhuang Institute of Agricultural Modernization; the Fengqiu Agricultural Ecological Experimental Station and Huaiyuan Agricultural Ecological Experimental Station of the Institute of Soil Science; the Shahe and Yanjin Experimental Stations of the Lanzhou Institute of Desert Research; the Xindian Experimental Station of the Nanjing Institute of Geography and Limnology. In the 1980s, the Institute of Geography of CAS did similar work to agricultural regionalization in the agricultural development of Yucheng County, Shandong, while different forms and methods were used. In the 1950s and 1960s, small-scale pilot tests were conducted in Yucheng County to develop agriculture in areas with poor drainage, and evident yield increase was rapidly achieved. In the 1980s, the scope of work was expanded to the whole Yucheng County. Experiments were arranged based on field investigation. The research work was closely linked with the promotion work, and the agricultural productivity of the county was continuously improved. Since 1990, the experience gained from Yucheng has been extended to northwest Shandong. Research and development were conducted in different areas and the actual achievements were remarkable. Such work had three characteristics: first, it was long-term; second, it was closely combined with production; and third, it was mainly based on experiments, particularly development experiments. The experimental work in the Yucheng Station had all these three characteristics (Huang et al., 1993). This section primarily summarizes the important contributions of physical geography to the construction of major grain production bases in the North China Plain through its interdisciplinary advantages.

\subsubsection{Application of saline-alkali soil improvement technology}

In 1954, with cooperation between the Institute of Geography of CAS and relevant departments and units of the Ministry of Water Resources, the soil investigation team conducted a 
systematic investigation of the soil in the North China Plain, under the leadership of Xiong Yi and Xi Chengfan of the Nanjing Institute of Soil Science. A set of 1:200,000 soil atlas has been completed, and a monograph of "Soil in North China Plain" was compiled, which provided basic data for drought, flood and salinization control in the North China Plain, and presented a comprehensive control plan. According to the law of water and salt movement and the conditions of resources and environment, improvement measures can be summarized into three categories: water conservancy, agricultural, and chemical. Owing to the complexity of formation conditions and properties of saline soil, researchers tend to emphasize the importance of soil improvement by comprehensive measures while studying and applying one single technology (Sun, 2005). Before the 1990s, the comprehensive measures of saline soil improvement emphasized the combination of water conservancy projects and agricultural and biological measures. The water and salt balance of a region or basin should be adjusted and controlled by irrigation and drainage. In the planning and design of irrigation and drainage systems, various measures such as drainage, irrigation, regulation, storage, and compensation were comprehensively used to control the irrigation water volume, the groundwater level and the dynamic change of water and salt, to achieve the comprehensive treatment of drought, flood, salt, and salinization (Yu, 2001).

Flushing and drainage are important measures and basic conditions for saline soil improvement through water conservancy. For saline soil areas where it was difficult to conduct artisanal drainage through deep ditches, the method of well irrigation and well drainage was adopted. Through the combination of shallow, medium, and deep wells, a well-ditch-channel system was formed, and measures such as drainage, irrigation, storage, and compensation were integrated (Sun, 2005). Well irrigation and well drainage is suitable for areas with high groundwater levels, high soil permeability, aquifers with certain thicknesses, and water quality suitable for irrigation. In combination with well irrigation, well drainage, and other agricultural measures, geographers presented a comprehensive supplementary technology of "well, ditch, flat, fertilizer, forest, and reform" (Cheng, 1993). For saline water areas with a high salt content in soil and a high level of mineralization in groundwater, the technique of using shallow well groups and strong drainage and irrigation effectively facilitated the rapid desalination of cultivated soil (Pang, 1990). The Yucheng Comprehensive Experimental Station also built a system of fish ponds and raised fields. The system raised farmland and increased the water and salt exchange rate between fish ponds and the raised fields, to realize rapid soil desalination and bring about corresponding economic and ecological benefits (Cheng, 1993). For alkaline soil, Nanjing Institute of Soil Science of CAS presented an effective measure to improve crusted alkaline soil with gypsum or phosphogypsum. Combined with deep ploughing, the effect of applying 200 to $300 \mathrm{~kg}$ of gypsum or phosphogypsum per $\mathrm{mu}(15 \mathrm{mu}=1 \mathrm{ha})$ was obvious. In the Tianranwenyanqu River Basin, measures were also taken to improve the saline-alkali soil by dredging and raising the ground to prevent the return of soil salt (Wang, 1987). These measures achieved favorable results.

In the coastal saline area with water shortages in the Huang-Huai-Hai Plain, innovative technologies were developed, including the activation, utilization, and regulation of shallow groundwater, the salt dynamics and regulation under well irrigation conditions and soil fertility and regulation (Tian, 1992). In coastal saline land, the groundwater depth is shallow, and it is difficult to reduce the groundwater level through water conservancy projects. In 
addition, there are key problems including the high degree of groundwater mineralization and poor soil structures. Using biological organic fertilizers, the soil structure can be improved rapidly, and the capillary channels can be cut off. Consequently, the crop stress resistance is improved. Combined with salt tolerant crops and agronomic control technologies, a comprehensive supporting technology for rapid improvement of coastal saline land was proposed.

\subsubsection{Application of aeolian sandy soil improvement technology}

Aeolian sandy soil is also an important type of degraded soil in the Huang-Huai-Hai Plain, covering an area of about $20,300 \mathrm{~km}^{2}$. There are $8,300 \mathrm{~km}^{2}$ of dune-shaped sandy soil and undulating sandy soil, and $12,000 \mathrm{~km}^{2}$ of flat sandy soil. In addition, the Yellow River irrigation also caused extensive silt sedimentation annually, forming a large area of bare sandy land (Sun, 2005). Through extensive practice, it was proposed that the basic control scheme of seasonal aeolian desertification in the semi-humid areas of the Huang-Huai-Hai Plain was that "water conservancy should come first; the hills should be flattened and the sand should be fixed; the forest network should be constructed; fruit-crop intercropping should be adopted; land use and maintenance should be combined." The supporting technologies for the control and development include: sand fixation and hill flattening, construction of the farmland shelterbelt system, cultivation of economic forests in sandy soil, fertilizing and soil improvement in sandy soil, and three-dimensional agricultural cultivation in sandy soil.

Taking the prevention and control of wind erosion and the reversal of aeolian sandy soil in Yucheng County as a representative, the supplementary technologies of "regulation and control through water conservancy, combination of forest and grass, biological coverage, and three-dimensional agriculture" for comprehensive treatment were established. These included the division of sandy soil by channels, forests, roads, and fields, forming an overall network pattern. The supplementary projects were used to carry out macro-control of the comprehensive treatment of aeolian sandy soil. The protection system made of trees, shrubs, and grass was established. Simultaneously, the water conservancy system of channels and wells and the wind erosion prevention system with intercropping under the protection of forest network were formed. After the transformation of aeolian sandy land, development approaches differed. Examples include the Xiajin sandy land ecological agriculture model and the Yanjin sandy land ecological agriculture model (Sun, 2005). After decades of comprehensive control, development, and utilization, most of the saline-alkali land and aeolian sandy land in the Huang-Huai-Hai Plain was improved and became high-yield farmland (Figure 3). The technical achievements of the transformation of the low-yield fields in the Huang-Huai-Hai Plain won the special prize of the National Science and Technology Progress Award.

\subsection{Permafrost engineering research provides scientific support for permafrost engi- neering and large-scale construction in cold regions of China}

China has a permafrost area of 2.15 million $\mathrm{km}^{2}$, ranking 3rd largest in the world (Zhou et al., 2000). The construction of large-scale projects in permafrost areas faces severe challenges (Cheng and He, 2001). Representative projects include the Qinghai-Tibet Railway, the Qinghai-Tibet Highway, and the high-speed railways in the cold regions. They also represent the world's leading construction technologies for major projects in permafrost 


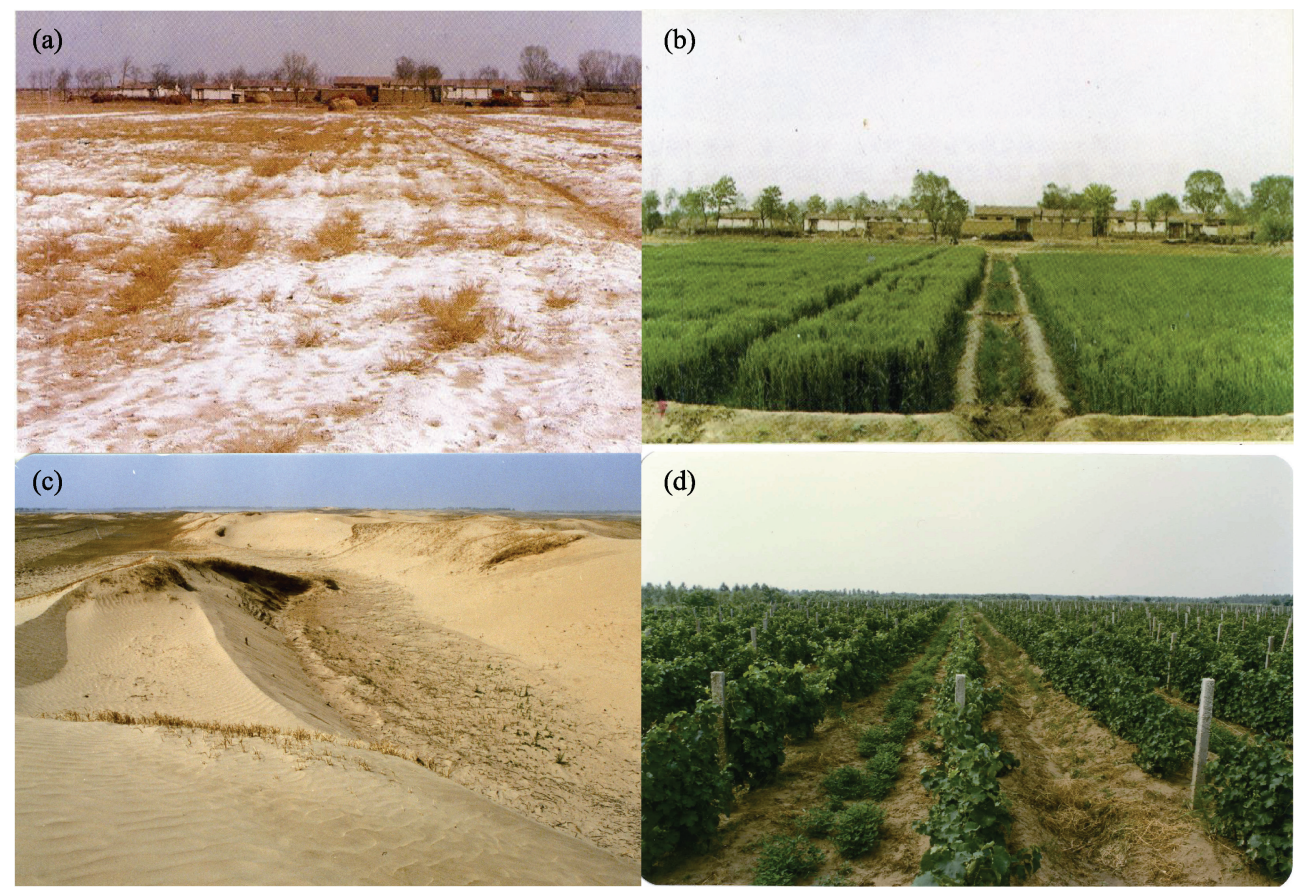

Figure 3 Comparison of saline-alkali soil and aeolian sandy soil before and after treatment in the Huang-Huai-Hai Plain; a and b show the results of wheat planting in the Beiqiuwa of Yucheng in the same year of heavy saline-alkali soil treatment using the shallow well group and strong drainage and irrigation technology (May 1990); c and d show the results of grape planting in Shahewa of Yucheng in the sandy land of an ancient river channel after treatment with the comprehensive aeolian sandy soil reversal technology (March 1989).

regions. The permafrost subgrade projects of the Qinghai-Tibet Railway and the Qinghai-Tibet Highway, as well as the subgrade projects of the high-speed railway in seasonally frozen ground region of Harbin-Dalian, demonstrate the major progress in China's construction technologies in permafrost and cold regions engineerings. Another report on the progress in the fundamental research of permafrost (Chen et al., 2019) summarizes the geographical research achievements in permafrost engineering by Chinese researchers.

\subsubsection{Permafrost subgrade engineering of the Qinghai-Tibet Railway}

The Qinghai-Tibet Railway is the highest and longest plateau railway in the world. It passes through a continuous permafrost area of more than $550 \mathrm{~km}$. The permafrost in the Qinghai-Tibet Plateau is mostly warm permafrost, with high ice content. Therefore, it is vulnerable to the influence of engineering and climate warming resulting in thawing and subsidence (Wu et al., 2007; Ma et al., 2009). Therefore, the key challenges in the construction of the Qinghai-Tibet Railway were to prevent thawing subsidence of the subgrade made of warm and ice-rich permafrost and ensure subgrade stability (Cheng and He, 2001; Wang, 2002).

The team led by Academician Cheng Guodong proposed a creative design method of cooling the subgrade and reducing the permafrost temperature based on the regulation of heat conduction, convection, and radiation. The subgrade is cooled by reducing the heat introduced into the subgrade soil. The key is to maintain the thermal stability of permafrost, to 
achieve the goal of protecting the stability of the subgrade and other railway structures. This method solved the key technical problems for the construction of the Qinghai-Tibet Railway in permafrost regions and tackled the worldwide problem of subgrade instability with warm and ice-rich permafrost. A complete set of road construction technology based on the regulation of heat conduction, convection, and radiation of permafrost subgrade was presented. Moreover, the theory and method for the long-term stability evaluation of permafrost engineering were established, the technical problems of permafrost subgrade construction under the influences of climate change and engineering thermal disturbance were tackled, and the innovation and breakthrough of the theoretical research of permafrost engineering were promoted (Ma et al., 2002; Cheng, 2003a; 2003b). The research results were fully applied in the design and construction of the Qinghai-Tibet Railway and ensured the successful construction and safe operation of the Qinghai-Tibet Railway. The average speed reaches 100 $\mathrm{km} / \mathrm{h}$, the highest permafrost region railway speed in the world. In 2008, the Qinghai-Tibet Railway was awarded the special prize in the National Science and Technology Progress Awards. Cheng Guodong and Ma Wei were selected as foreign fellows by the Russian Academy of Engineering. In 2014, Academician Cheng Guodong won the Lifetime Achievement Award from the International Performance Association (IPA), showing China's permafrost engineering research is world leading.

\subsubsection{Permafrost subgrade engineering of the Qinghai-Tibet highway}

The Qinghai-Tibet Highway (National Highway 109) was constructed in the 1950s, crossing the Kunlun Mountains and the Tanggula Mountains, and passing through a permafrost area extending more than $700 \mathrm{~km}$. It laid the foundation for traffic engineering in the permafrost regions of the plateau. More importantly, China successfully built massive asphalt pavements on the Qinghai-Tibet Plateau featuring cold climate, severe freeze-thaw cycles, and strong ultraviolet radiation, breaking through the "scientific forbidden zone" where asphalt pavement was believed to be impossible in permafrost regions (Wu et al., 2005; Wang et al., 2008).

In the early stages, there was no knowledge of permafrost; therefore, no measures were taken to prevent permafrost changes when the Qinghai-Tibet Righway was constructed. Therefore, the subgrade height was generally low, which led to subsequent irreversible permafrost engineering hazards. The thawing subsidence of permafrost, road frost boiling, and wave subsidence in the longitudinal direction of the subgrade, etc. seriously impacted driving safety (Wu et al., 2002). From 1973 to 1985, the Qinghai-Tibet Highway was upgraded to the second class, in which the subgrade was widened, and asphalt pavement was constructed. The pavement conditions were improved; however, the asphalt pavement had strong heat absorption and blocked evaporation and heat dissipation. The temperature under the pavement was more than $5^{\circ} \mathrm{C}$ higher than normal. The long-term heat accumulation led to the formation of the subgrade thawing interlayer under the asphalt pavement, subgrade thawing subsidence and pavement subsidence, which affected the normal operation of the highway. From 1992 to 1996 and from 1996 to 1999, the first-phase and second-phase renovation projects of the Qinghai-Tibet Highway located in permafrost regions were conducted, respectively. The embankment was raised in some sections to protect the permafrost. However, the huge difference of heat absorption between the sunny and shady sides of the embankment in the plateau environment led to the decrease of the artificial upper limit of the 
subgrade on the sunny side, resulting in the longitudinal cracking of the sunny side and the aggravation of the longitudinal asymmetric deformation of the subgrade (Wang and Mi, 1993; Wu and Tong, 1995; Zhang et al., 2000). From 2002 to 2004, renovation of the Qinghai-Tibet Highway during the construction of the Qinghai-Tibet Railway was conducted. The idea of "actively protecting permafrost" was widely absorbed. The criteria of permafrost division and classification for highway construction, the scale and black surface effect of highway embankment in permafrost areas, and the design, construction, and maintenance technologies of highway pavement structure and materials in permafrost areas were presented. All these advances ensured the safe operation of the Qinghai-Tibet Highway and enhanced the research level on highway permafrost engineering in China (Wang et al., 2008). In 2008, it won first prize in the National Science and Technology Progress Awards. On August 1, 2018, the first highway passing through the permafrost region of the Qinghai-Tibet Plateau in China, the Gonghe-Yushu highway, was built successfully. It showed a higher level of research on permafrost engineering for highway construction in China and laid a solid foundation for the construction of the Qinghai-Tibet Highway in the future.

2.6.3 Frozen ground subgrade engineering of high-speed railway seasonally frozen ground region of Harbin-Dalian

The Harbin-Dalian High-speed Railway is the first high-speed railway in cold regions in the world. The railway passes through the piedmont plain in the middle of Northeast China. The maximum natural frost depth along the railway ranges from $0.88 \mathrm{~m}$ to $2.90 \mathrm{~m}$ in winter. The groundwater level is shallow, and frost heave was one of the major issues for the Harbin-Dalian high-speed railway. In the design, the temperature was determined as the control factor and reasonable values for seasonal frost depths should be carefully considered. The frost heave classification of the replaced soil was determined based on the lithologic conditions (soil properties). The auxiliary measures were to control (cut, drain, and block) the direction of water migration in different stages of the soil frost heave process. The goal was to control the seasonal frost heave of subgrade soil and the foundation upfreezing, to ensure the stable operation of high-speed railways in cold regions (Ye et al., 2007; Liu et al., 2011). However, with limited knowledge of micro frost heave, frost heave deformation of the subgrade happened frequently after the railway was open to traffic, which seriously affected the safe operation of the high-speed railway (Shi et al., 2014; Cai, 2016). At the initial stage of the operation of the Harbin-Dalian High-speed Railway, two operational timetables were implemented in winter and summer, respectively. The corresponding running speeds were $200 \mathrm{~km} / \mathrm{h}$ and $300 \mathrm{~km} / \mathrm{h}$. After treatment, it has been operating at a speed of $300 \mathrm{~km} / \mathrm{h}$ all year round since December 1, 2015. The successful construction of the Harbin-Dalian High-speed Railway not only deepened the research of micro frost heave, but also laid an important scientific and technological reference for the construction of high-speed railways in the cold regions of the world.

\subsection{Studies on the anormal geographical distribution and mechanism of chemical element contribute to the prevention and control of endemic diseases in China}

Human health is closely related to the geographical environment of inhabitants. The negative effects of chemical element anomalies and regional differentiation on human health lead to the occurrence of endemic diseases. In China, endemic diseases related to the chemical 
factors of the geographical environment include Keshan Disease, Kashin-Beck Disease, Iodine Deficiency Disease, Endemic Fluorosis, and Endemic Arsenism. In the late 1960s, at the request of the leading group for the prevention and control of endemic diseases in North China of the CPC Central Committee and the Ministry of Health, the Institute of Geography, together with other geoscience institutes of CAS and the Departments of Health and CDC, investigated and studied the environmental causes and corresponding prevention and treatment methods of endemic diseases for over 50 years. In the areas of geographic epidemic analysis and prevention of Keshan Disease, Kashin-Beck Disease, Iodine Deficiency Disease, Endemic Fluorosis, Endemic Arsenism, and Plague, they have undertaken a large number of national and local scientific research projects and won nearly 30 national and provincial awards, making great contributions to the etiologic study and prevention of endemic diseases in China (Yang et al., 2010).

2.7.1 Finding a natural low selenium belts coincide with the distributions of Keshan Disease and Kashin-Beck Disease, identified the environmental causes of the two diseases and provides an eco-economic way for their prevention and control

From the late 1960 s to the early 1980 s, scientists of the Institute of Geography of CAS found that Keshan Disease and Kashin-Beck Disease are mainly distributed from the northeast to the southwest of China, with brown soil, drab soil and purple soil in temperate (warm) forests and forest grasslands as the central axis (GEED, 1979; 1985; Tan et al., 2002). Through large-scale investigation and sampling, they found a low selenium belt in the natural environment from the northeast to the southwest of China. The geographical distribution of Keshan Disease and Kashin-Beck Disease is highly consistent with that of the low selenium belt in the natural environment (GEED, 1981; Hou and Zhu, 1984); thus, it was determined that Keshan Disease and Kashin-Beck Disease are related to the selenium deficiency in the natural environment. The geographical distribution law of selenium in the environment and organisms and its mechanism were illustrated from the perspective of geographical differentiation. These findings indicated breakthroughs in the etiology of Keshan Disease and Kashin-Beck Disease (Tan, 1989; Li et al., 2017). This research achievement won the National Science Conference Award in 1978, the Major Scientific and Technological Achievement Award of CAS, and the first prize of the Scientific and Technological Progress Awards of CAS in 1986. In the 1980s and 1990s, the index system of selenium zoning in the geographical ecosystem was built, and an ecological landscape map of selenium was prepared (Figure 4). The relationship between Kashin-Beck Disease and Keshan Disease and the selenium deficiency was systematically demonstrated from an environmental perspective (RTEED, 1986), and diseases prevention and control strategies based on selenium supplements either from agriculture or from food were presented. The strategies were applied in the Loess Plateau Area. The departments of health made use of these achievements to extensively promote selenium supplementation in disease areas to improve the selenium intake of residents, to prevent and control the diseases (Li et al., 1991; Li et al., 1999). Since the beginning of the 21 st century, the Institute of Geographic Sciences and Natural Resources Research (IGSNRR) of CAS conducted systematic and dynamic studies on the active areas of Kashin-Beck Disease in the Qinghai-Tibet Plateau. The research results revealed the relationship between the epidemic law of Kashin-Beck Disease and its relation with dietary selenium content in the disease areas and helped implement diet structure adjustments to im- 
prove the selenium intake of the residents. In addition, the practice of dietary adjustment was conducted in primary schools within Kashin-Beck Disease areas in Tibet for many years, which significantly reduced the prevalence of the disease among children in this area and achieved the goal of prevention and control (Yang et al., 2005; Li et al., 2008; Chen et al., 2015; Wang et al., 2017).

\subsubsection{Compilation of "The Atlas of} Endemic Diseases and Their Environments in the People's Republic of China" systematically revealed the distribution of endemic diseases in China and their relationship with the geographical environment

Entrusted by the office of the leading

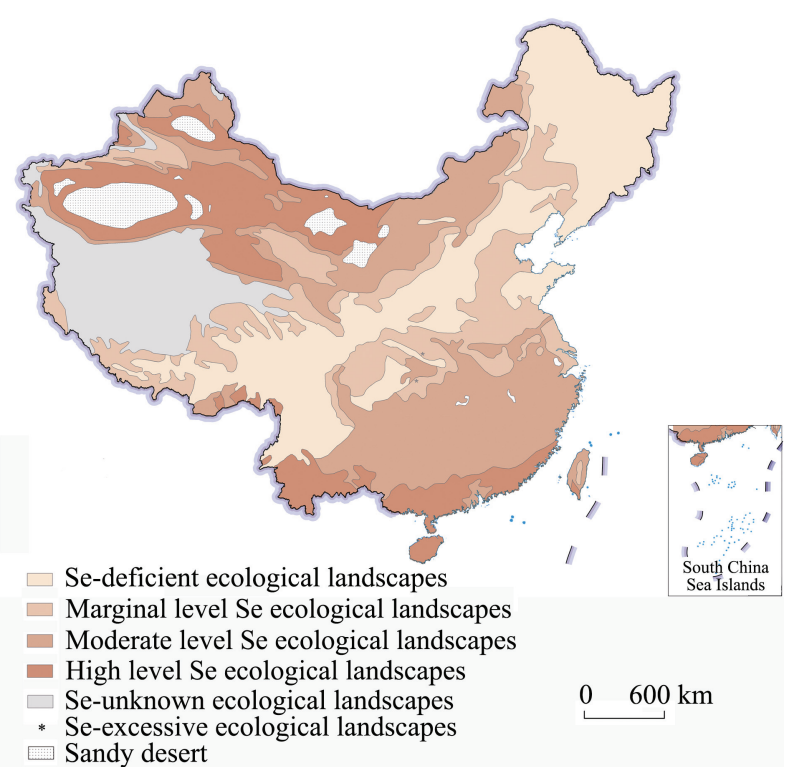

Figure 4 Distribution of low selenium belt in China (Research Team of Environment and Endemic Disease, 1986; Guo et al., 2017) group for the prevention and control of endemic diseases of the CPC Central Committee, relevant research institutes of CAS and the office of the leading group took 10 years to compile and publish the "Atlas of Endemic Diseases and Their Environments in the People's Republic of China" (CEDTE, 1989). For the first time, the atlas systematically and comprehensively showed the distribution and epidemic characteristics of Keshan Disease, Kashin-Beck Disease, Iodine Deficiency Disease (including endemic cretinism), and Endemic Fluorosis in China. It also demonstrated the relationship between such endemic diseases and the ecological environment, especially chemical environmental factors. The atlas provides a scientific basis for the etiology of endemic diseases in China and made a great contribution to the allocation of prevention and control forces for endemic diseases, as well as the development of prevention and control schemes for endemic diseases according to local conditions. Therefore, relevant research institutes were awarded the title of "National Advanced Group for Control and Prevention of Endemic Diseases" by the office of the leading group for the prevention and control of endemic diseases in north China of the CPC Central Committee. They also won many awards such as the National Science and Technology Progress Award.

2.7.3 Compilation of "The Atlas of Plague and Its Environment in the People's Republic of China" systematically revealed the spatiotemporal epidemic law of plagues and expounded the type, distribution, and long-term existence mechanism of Plague foci

The "Atlas of Plague and Its Environment in the People's Republic of China", compiled by the IGSNRR of CAS, was published in 2000 (Liu et al., 2000). The atlas objectively and scientifically expounded the spatial and temporal characteristics of Plague epidemics in China for more than 200 years. It also revealed the causes and classification of natural epidemic foci, the ecological and biochemical characteristics of Yersinia pestis, and the geo- 
graphical differentiation of host and media and their relationship with the environment. Moreover, the distribution and formation of Plague foci were closely related to the geochemical environment, which provided a new idea for the study of Plague foci and plague control (Yang et al., 2010). On this basis, the relationship between the outbreak and epidemic of Plagues and climate factors (such as drought and flood) was established (Yang et $a l ., 2000)$. Favorable habitats for various Plague foci were analyzed, and the spatial change of Plague foci with climate change was predicted, which provided scientific basis for plague control (Li et al., 2001).

2.7.4 The dose-response relationships between environmental arsenic and fluorine exposure and Endemic Arsenism and Endemic Fluorosis was established, which provided scientific and technological support for the prevention and control of the disease and the implementation of National Drinking Water Safety project

Since the discovery of endemic arsenism in China in the late 1980s, Chinese geographers have been involved in the study of its corresponding geographical epidemiology and environmental prevention and control. The geographical and epidemiological investigation identified the spatial distribution and geographic epidemic characteristics of Endemic Arsenism and Endemic Fluorosis in China and the distribution rule of arsenic and fluorine anomalies in the environment (Hou et al., 2002; Jin et al., 2003). The environmental characteristics and mechanism of the arsenic anomaly in groundwater in drinking-water type arsenism areas of China were clarified (Guo et al., 2013). Geographers conducted systematic investigations on the drinking-water type and coal-burning type arsenism and fluorosis and brick-tea-type fluorosis in China, established the dose-response relationship between arsenic and fluoride exposures in drinking water and coal combustion and arsenism and fluorosis, as well as the dose-response relationship between fluoride exposure in tea drinking and fluorosis in the disease areas were expounded (Li and Wang, 2001; Yang et al., 2017), and the influence of water quality improvement on the epidemic law of arsenism was systematically revealed (Wei et al., 2018). It provided an important scientific basis for the prevention and control of endemic arsenism and fluorosis and the implementation of national drinking water safety processes as stated in the 11th and 12th Five-Year Plans (2006-2015). In addition, the IGSNRR of CAS also found that selenium supplementation can effectively alleviate the clinical symptoms of arsenism patients and reduce the arsenic level of arsenism patient, which provided new ideas for the prevention and control of arsenism (Yang et al., 2002). High-efficiency fluorine and arsenic retention agents were developed, which provided economic and practical technologies for reducing arsenic and fluorine exposure in coal combustion (Yu et al., 2004).

\subsection{Observation and monitoring facilitates innovative research on the physical geo- graphical processes}

Observation and monitoring is a necessary means for process analysis, quantitative research, and mechanism analysis in physical geography. It strongly supports and guarantees the innovative development of physical geography and provides systematic technological and theoretical support for China's agricultural production, ecological construction, environmental protection, and sustainable development in China. 
2.8.1 The construction of physical geographical observation stations promotes the quantitative study of geographical processes

To reveal dynamic geographical processes quantitatively, Huang Bingwei proposed the introduction of knowledge and new technologies of mathematics, physics, chemistry, biology, and other disciplines into geography in the 1950s. He also suggested it was necessary to carry out experimental research to study the physical, chemical, and biological processes of the land surface system, and to investigate the regularity of energy conversion and material migration. Thus, the physical geography community in China began to attach importance to field experimental research and set up stations. It promoted the important transformation of geographical research from single region to the combination of point, zone, and area and from a qualitative analysis to a combination of both qualitative and semi-quantitative analysis (Yang et al., 2010).

In the 1950s, the observation and experiments were mainly carried out in hydrologic research related to deserts, glaciers, and lakes. In the 1960s, the observation and experiments on the heat and moisture balance, snow and avalanche, and slope erosion were conducted in fixed locations (Hang et al., 1990). In the late 1970s, the Yucheng Comprehensive Experimental Station was established, laying the foundation for the systems of observation, experiment, and research of physical geographical elements and processes. In the 1980s and 1990s, the field stations strengthened network construction. While persisting in long-term observation and focusing on national needs, attention was also paid to the original innovation in cutting-edge research (SRDFS, 2014). In 1988, CAS established the Chinese Ecosystem Research Network (CERN). CERN systematically standardized the observation indices of biology, climate, and soil in field stations, and unified the observation indices and data through series technical processes, specifications, and equipment. Simultaneously, the dynamic changes of the structure, function, pattern, and process of ecosystems were continuously tracked and compared to explore the optimization of ecosystem management (Sun, 2006).

At the beginning of the 21st century, the National Ecosystem Research Network was launched based on the CAS CERN observation network. At present, a national ecosystem field monitoring system and the corresponding data sharing system have been established. In addition, the monitoring index system and its technical specifications have been formulated, covering major ecosystem types and key areas in China. The system consists of 18 national farmland stations, 17 national forest stations, 9 national grassland and desert stations, and 7 national water body and wetland stations.

In field stations (such as CERN), various scientific observation and experimental studies have successively been conducted on subjects including the ecosystem structure and function, carbon and water flux observations, climate change adaptation experiments, biodiversity monitoring, farmland nutrient and water balance, and the theory and technology for high-yield and high-efficiency ecological agriculture. The major theoretical and technical issues in climate change response, biodiversity conservation, sustainable high-yield agricultural production and ecosystem restoration were studied in depth. In particular, significant progress has been made in the key ecosystem processes and changes in agricultural development, climate change and the ecosystem response and adaptation, biodiversity conservation and ecosystem stability, and the evolution and degradation of fragile ecosystems (Yu 
and $\mathrm{Yu}, 2013)$. Overall, the construction of the field observation network has been continuously improved, which provides support for the interpretation of the interaction mechanism of geographical elements. Based on existing observations, the natural process and mechanism was revealed, forming a major branch of geographical research (Song and Leng, 2005). The research results have won the first prize of the National Science and Technology Progress Award.

2.8.2 Scientific and technological achievements of observation and monitoring systems support the construction of national ecological civilization

Over the past 70 years, the achievements of experimental geography in China based on the field stations have been effectively commercialized, making important contributions to national food and ecological security. According to the long-term observation and experimental research in the field stations, the selected optimization models were promoted and applied widely, to realize the integration of regional ecological protection and social development. Through demonstration and application, they served national ecological construction and provided scientific basis for sustainable development (Sun, 2006). Different types of field stations in China have established demonstration zone to develop ecosystem management models for ecological agriculture, grassland protection and utilization, ecological restoration, and degraded lake management. They provided scientific and technological support for ecological civilization construction such as natural ecological protection, ecological restoration and modern agricultural production, and promoted regional industrial development in China (Yu and Yu, 2013). The Yucheng Comprehensive Experimental Station presented a series of agricultural technologies and models, including comprehensive supplementary technologies for saline-alkali soil treatment, medium- and low-yield fields' treatment, agriculture-husbandry integration and high yield and high efficiency modern agriculture. Simultaneously, the demonstrations of relevant agricultural technologies and production modes were conducted, which had a profound impact on the North China Plain and even the whole country. A series of research was conducted to support the commercialization of mediumand low-yield fields in the Huang-Huai-Hai Plain and won the first and second prizes of the National Science and Technology Progress Award.

\subsection{The geographical detector for the measurement and attribution analysis of spatial stratified heterogeneity}

Spatial heterogeneity refers to the phenomenon that within-strata variance is less than between-strata variance (Dutilleul, 2011), which is another important property of geographic data besides spatial autocorrelation. The spatial autocorrelation of geographical data has been presented for more than half a century. It has been widely used in studies like spatial interpolation and spatial regression (Matheron, 1963; Cliff and Ord, 1981; Anselin, 1988; Haining, 1990) and has become the theoretical basis of spatial statistics (Wang et al., 2014). Spatial autocorrelation based on spatial statistics assumed that the population of the research object has spatial stationarity, and the samples have independent and identically distributed properties. However, in reality, the above assumptions are often not satisfied as geographical phenomena often have spatial heterogeneity (Dutilleul, 2011).

Researchers both locally and abroad conducted long-term studies on various forms of 
spatial heterogeneity and made a series of important achievements. Prior studies showed that spatial heterogeneity is primarily manifested in the following aspects: (1) spatial autocorrelation. This phenomenon indicates that things close to each other in space are similar, while things far away in space are different (Matheron, 1963); (2) spatial local heterogeneity. This phenomenon shows that there are differences between the geographical attributes in the local area and the neighboring areas. There exist many geological models based on this property, such as $\mathrm{G}_{\mathrm{i}}$ statistics (Getis and Ord, 1992), local indicator of spatial association (LISA) (Anselin, 1995), SaTScan (Kulldorff, 1997), point pattern statistics (Upton and Fingleton, 1985; Diggle, 2003), and geographically weighted regression (GWR) (Fotheringham et al., 2000); (3) spatial hierarchical heterogeneity (SHH). This phenomenon shows the heterogeneity of geographical attributes at different spatial scales (Openshaw, 1984; Goldstein, 2011). There are many geological models based on this property, such as the semivariogram, Ripley's K statistics (Ripley, 1977), multilevel model (MLM) (Goldstein, 2011) and Bayesian hierarchical model (BHM) (Haining, 2003; Banerjee et al., 2004); (4) spatial stratified heterogeneity (SSH) (Wang et al., 2016). This phenomenon shows that geographical attributes have great similarity within strata, while there are great differences between strata. The meaning of "strata" in statistics roughly corresponds to "class" or "region" in geography, which is totally different from "layer" or "coverage" in geography, especially in GIS. The first three types of heterogeneity have been widely studied and applied to practices; however, there are still no satisfactory methods for the measurement and attribution analysis of spatial stratified heterogeneity.

Spatial stratified heterogeneity exists widely in nature, such as climate zones and land use types. It has opened a window for mankind to explore geographical laws and investigate the mechanisms behind geographical patterns since Aristotle and Humboldt. The geographical detector, $q$-statistic, is a new statistical theory and method for the measurement and attribution analysis of spatial stratified heterogeneity (Wang et al., 2010; 2016; Wang and Xu, 2017). The principle is to assume that the research objects can be divided into several strata (Figure 5). If the sum of the variance of each type or region strata is less than the total variance of the whole research area, there is spatial heterogeneity. If two variables have a causal relationship, their spatial distributions tend to be coupled, and their coupling degree can be measured by $q$-statistics. The range of $q$ values is $[0,1]$. When an attribute has perfectly stratified heterogeneity, or two variables are perfectly coupled, then $q=1$. When there is no stratified heterogeneity for an attribute, or the two variables are independent, then $q=0$. The

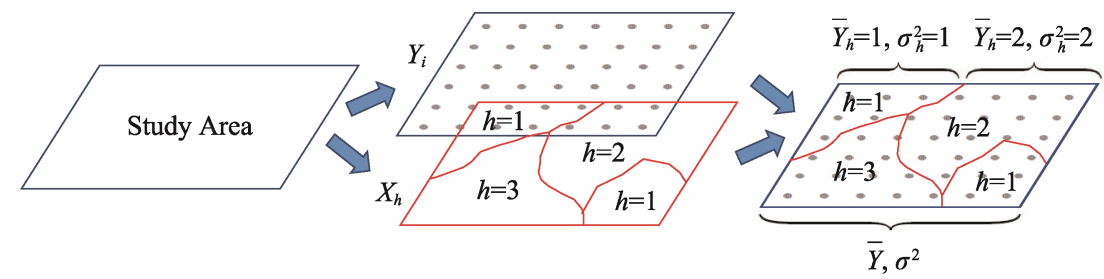

Figure 5 Principle of the geographical detector (after Wang and $\mathrm{Xu}, 2017$ )

The study area consists of two layers: the interpreted variable of $Y$ and the spatial layer of $X$; $X$ can be used to express geographical spatial stratified heterogeneity. $\bar{Y}$ and $\sigma^{2}$ are the mean and variance of the whole study area, $\bar{Y}_{h}$ and $\sigma_{h}^{2}$ are the mean and variance of the $h$ th layer. 
spatial differentiation or coupling degree of two variables is $q=100 \%$. Compared with the traditional model, the $q$-statistic of the geographical detector has no linear hypothesis, and the sample representation is increased through stratification. With the same sample size, it has a stronger statistical advantage compared to ordinary linear regression and could identify potential causal relationships. This method can also calculate the generalized spatial interaction between two variables, including multiplication, and overcome the problem of collinearity of independent variables in traditional models.

Compared with conventional methods, the geographical detector has clear geographical meaning; in addition, its principle is universally applicable and its form is simple. Moreover, the statistical results have clear physical meaning. The geographical detector was first introduced in 2010, and further developed in 2016 and 2017. At present, it has been applied to more than 50 branches of natural and social sciences by scholars from 26 countries and regions, and more than 800 articles have been published in Chinese and English (as of January $31,2020)$. In these studies, this method was mainly used to measure the spatially stratified heterogeneity of geographical elements, analyze the nonlinear driving factors of spatial stratified heterogeneity, and study the interaction of multiple explanatory variables (more details can be found on http://www.geodetector.cn).

\section{Outlook}

Over the past 70 years, through the comprehensive study such as physical geographical regionalization, eco-geographical regionalization, comprehensive regionalization, and future risk regionalization, physical geography provided basis for land utilization in China. The investigation of land resources, the spatial difference and mechanism of land use and land cover provided a plan for the coordinated development of the man-land relationship in China. The systematic research of natural disaster processes and risk assessment, such as hazard (e.g. the debris flow process), integrated risk assessment from single disaster to multiple disasters, climate change risk assessment, and disaster risk assessment, directly served the needs of national disaster reduction and relief. The research of processes and control technologies of stony desertification in southwest China, desertification and wind erosion of soil in arid and semi-arid areas of northwest China, and soil and water conservation in east monsoon area promoted scientific desertification control in China. According to national needs, physical geographers were also actively involved in the transformation of midiumand low-yield fields composed of aeolian sandy soil and saline-alkali soil in the Huang-Huai-Hai Plain. They successfully developed improvement technologies for aeolian sandy soil and saline-alkali soil, which gained remarkable achievements. In China, problems such as frost heave deformation were encountered in the construction of ordinary and high-speed railways as well as ordinary roads and highways in permafrost regions. Physical geographers were actively engaged in theoretical and practical research to provide scientific support for the permafrost engineering projects and large-scale construction in cold regions in China. Physical geographers also explored the relationship between endemic diseases (such as Keshan Disease, Kashin-Beck Disease, Endemic Arsenism, etc.) and the geographical environment. They proposed measurements that made important contributions to the prevention and control of endemic diseases through the relationship between the geo- 
graphical distribution of chemical element anomalies and the spatial distribution of endemic diseases. The modern geographical detector method provided a statistical tool for the research of geographical spatial heterogeneity, and the development of observation and monitoring in fixed locations ensured innovative research on physical geographical processes and supported the construction of national ecological civilization. The applied research of physical geography made great contributions to the national socioeconomic development and ecological environment construction and won nearly 30 National Science and Technology Progress Awards, including two special prizes and five first prizes. A number of academic leaders in the research areas of application and practice of physical geography have also been cultivated. In the future, physical geography should be further integrated with human geography and geographic information science. Fundamental and applied studies should be actively conducted according to national needs and international trends at all times. The applied research of physical geography will be further expanded in the following three aspects.

The application of physical geography to sustainable socioeconomic development will continue to enhance. With 70 years of development, the physical geography community has presented a series of new paradigms, methods, and strategies for agricultural production, ecological construction, and regional sustainable development based on in-depth understanding and mastering of natural laws, playing a positive role in promoting science and technology. At present, physical geography has a bright future in China. Since the beginning of the 21 st century, sustainable development has been deeply rooted in minds, with an emphasis on the protection of the earth's ecosystem for human well-being and future generations (Griggs et al., 2013). The sustainable development goals (SDGs) proposed at the Rio Earth Summit in 2012 were designed to undertake the Millennium Development Goals (MDGs), which are the key goals of each country in the world from 2016 to 2030 (United Nations, 2015). In 2013, the International Council for Science (ICSU), the International Social Science Council (ISSC), and other institutions established the "Future Earth" plan (2014 - 2023) and promoted it as a scientific alliance to cope with global environmental change and promote global sustainable development. This plan emphasizes the combination of natural science research and sustainable socioeconomic development and provides scientific solutions to the key problems that currently plague human development. Also, it ensures the supply of food, water, biodiversity, and healthcare needed for human development and the effective management of other environmental functions and services (Future Earth, 2013; Qin, 2014). China has established resource conservation and environmental protection as its basic state policy and determined sustainable development as its national strategy. In the context of complicated status of global environmental change and human-land relationship, the Chinese government attaches great importance to ecological and environmental protection. In general, there are dual impacts from both international plans such as the sustainable development goals of the United Nations, and the "Future Earth", and domestic development needs such as construction of ecological civilization and a prosperous society, regional scientific expedition, and the Belt and Road Initiative. Thus physical geography characterized with fundamental and comprehensive regional research and embedded with a mechanism of integrated theory and practice, would strengthen its support for the sustainable development of society and economy, and further broaden its application in the construction of socialism 
with Chinese characteristics.

The application fields and scope of physical geography will be further expanded. Driven by global environmental change, relevant major international scientific programs have been launched successively, such as the International Biosphere Program (IBP), the Man and the Biosphere Program (MAB), the Millennium Ecosystem Assessment (MA), the International Geosphere-Biosphere Program (IGBP), and the International Human Dimensions Program on Global Environmental Change (IHDP). Current research on the geographic process pays more attention to the impact of human activities (Fu et al., 2006). In the new era, the development of physical geography needs more research and consideration of the impact and feedback of human activities on the natural environment. In this way, the objectivity and applicability of research results can be enhanced to correctly guide the implementation of the important development concept of "lucid waters and lush mountains are invaluable assets." In the future, the application fields and scope of physical geography should be actively expanded from the traditional comprehensive regionalization, desertification control, and agricultural production increase to climate change response, disaster risk governance and reduction, environmental pollution control, fragile ecology restoration, and ecosystem and natural environment services, which are closely related to human activities. Eventually, physical geography will be able to provide the government with more accurate and detailed decision-making suggestions and scientific basis.

The application of cutting-edge technology and cross disciplinary integration will enhance the applicability of physical geography. In the past 70 years, a series of remarkable advances have been made in the fundamental research of physical geography and the living environment in China (Chen et al., 2019), which provides an important theoretical basis for the application and practice of physical geography. Driven by the modern technological progress and interdisciplinary integration, physical geography can make great contributions to sustainable socioeconomic development, the integration of nature and social economy, and the construction of ecological civilization. In the past, physical geography actively learned from physical, chemical, and biological methods and techniques. Now, modern technologies such as the geographic information system and remote sensing should be taken as the main technical means of physical geography. The availability, continuity, and expansibility of geographic spatiotemporal data should be strengthened. Simultaneously, new technologies such as big data and artificial intelligence will receive more attention in physical geography. Moreover, with the in-depth interdisciplinary integration of physical geography, human geography, ecology and economy, physical geography will play a unique role in a broader scope and at a deeper level. Driven by the technological progress and interdisciplinary integration, the focus of physical geography has changed from the description and representation of geographical phenomena to the mechanism analysis of geographical processes. In the future, physical geography will focus on the prediction of changing trends. It will also contribute to socioeconomic development, the construction of ecological civilization and prosperous society, and the sustainable development at both national and regional levels in China.

\section{References}

Anselin L, 1995. Local indicators of spatial association: LISA. Geographical Analysis, 27(2): 93-115. 
Anselin L, 1998. Spatial Econometrics: Methods and Models. Dordrecht: Kluwer.

Bai Xiaoyong, Wang Shijie, Chen Qiwei et al., 2009. Spatio-temporal evolution process and its evaluation method of karst rocky desertification in Guizhou Province. Acta Geographica Sinica, 64(5): 609-618. (in Chinese)

Banerjee S, Carlin B P, Gelfand A E, 2004. Hierarchical Modeling and Analysis for Spatial Data. Boca Raton: CRC Press.

Borbély-Kiss I, Kiss A Z, Koltay E et al., 2004. Saharan dust episodes in Hungarian aerosol: Elemental signatures and transport trajectories. Journal of Aerosol Science, 35: 1205-1224.

Bureau of Wildland Survey and Design (BWSD) in Xinjiang Uygur Autonomous Region, 1958. Soil and its utilization in the middle Tarim River. Xinjiang Agricultural Sciences, (1): 8-10. (in Chinese)

Cai Degou, 2016. Test on frost heaving spatial-temporal distribution of high speed railway subgrade in seasonal frozen soil region. China Railway Science, 37(3): 16-21. (in Chinese)

Cai Qiangguo, Wang Guiping, Chen Yongzong, 1998. Process and Simulation of Erosion and Sediment Production in Small Watershed on the Loess Plateau. Beijing: Science Press. (in Chinese)

Cai Yunlong, 1996. Preliminary research on ecological reconstruction in karst mountain poverty areas of southwest China. Advance in Earth Sciences, 11(6): 602-606. (in Chinese)

Cai Yunlong, 2001. A study on land use/cover change: The need for a new integrated approach. Geographical Research, 20(6): 645-652. (in Chinese)

Cai Yunlong, 2010. New perspectives on physical geography. Geographical Research, 29(1): 1-12. (in Chinese)

Cai Yunlong, 2015. Study on Land Change in Karst Plateau Mountain Area of Guizhou. Beijing: Science Press. (in Chinese)

Cai Yunlong, Meng Jijun, 1999. Ecological reconstruction of degraded land: A social approach. Scientia Geographica Sinica, 19(3): 198-204. (in Chinese)

Cao S, 2008. Why large-scale afforestation efforts in China have failed to solve the desertification problem. Environmental Science \& Technology, 42: 1826-1831.

Chan Duo, Wu Qigang, Jiang Guixiang et al., 2016. Projected shifts in Köppen climate zones over China and their temporal evolution in CMIP5 multi-model simulations. Advances in Atmospheric Sciences, 33(3): 283-293.

Chen Chi, Park Taejin, Wang Xuhui et al., 2019. China and India lead in greening of the world through land-use management. Nature Sustainability, 2: 122-129.

Chen Fahu, Chen Shengqian, Zhang Xu et al., 2020. Asian dust-storm activities dominated by Chinese dynasty changes since 2000 BP. Nature Communications, 11: 920. doi: 10.1038/s41467-020-14765-4.

Chen Fahu, Fu Bojie, Xia Jun et al., 2019. Major advances in studies of the physical geography and living environment of China during the past 70 years and future prospects. Science China Earth Sciences, 49(11): 1659-1696. (in Chinese)

Chen Jie, Huang Wei, Jin Liya et al., 2018. A climatological northern boundary index for the East Asian summer monsoon and its interannual variability. Science China Earth Sciences, 48(1): 93-101. (in Chinese)

Chen Moxiang, Du Guoyuan, Wang Wenxian, 1959. Hydrogeological conditions and reclamation of waste land in the middle Tarim River. Scientia Geologica Sinica, (12): 377-382. (in Chinese)

Chen Xi, Bao Anming, Wang Xinping et al., 2017. Ecological effect evaluation of comprehensive control project in Tarim River Basin. Bulletin of the Chinese Academy of Sciences, 32(1): 20-28. (in Chinese)

Chen Xiaoqing, Cui Peng, You Yong et al., 2015. Engineering measures for debris flow hazard mitigation in the Wenchuan earthquake area. Engineering Geology, 194: 73-85.

Chen Xiaoqing, Cui Peng, You Yong et al., 2017. Dam-break risk analysis of the Attabad landslide dam in Pakistan and emergency countermeasures. Landslides, 14(2): 675-683.

Chen Yaning, Zhang Xiaolei, Zhu Xiangmin et al., 2004. Analysis on the ecological effects of water transport in the cutoff channel of the lower Tarim River, Xinjiang. Science in China (Series D), (5): 475-482.

Chen Yong, Liu Jie, Chen Qi et al., 1999. Earthquake Hazard Analysis and Earthquake Damage Prediction. Beijing: Seismological Press. (in Chinese)

Chen Zhuo, Li Hairong, Yang Linsheng et al., 2015. Staple food consumption and related selenium intake among residents in Kashin-Beck disease endemic areas of Lhasa municipality, China. Chinese Journal of Public Health, 31(7): 915-918. (in Chinese)

Cheng Guodong, 2003a. Construction of Qinghai-Tibet Railway with cooled roadbed. China Railway Science, 


\section{4(3): 1-4. (in Chinese)}

Cheng Guodong, 2003b. The influence of local factors on the distribution of permafrost and its inspiration to the design of Qinghai-Tibet Railway. Science in China (Series D), 33(6): 602-607. (in Chinese)

Cheng Guodong, He Ping, 2001. Linearity engineering in permafrost areas. Journal of Glaciology and Geocryology, 9(3): 213-217. (in Chinese)

Cheng Weixin,1993. Lowland Improvement and Environmental Ecology. Beijing: Science Press, 35-245. (in Chinese)

Cheng Zhigang, Zhang Yuanmeng, Xu Ying, 2015. Projection of climate zone shifts in the 21st century in China based on CMIP5 models data. Climate Change Research, 11(2): 93-101. (in Chinese)

Ci Longjun, 2005. Desertification and Its Control in China. Beijing: Higher Education Press. (in Chinese)

Cliff A D, Ord J K, 1981. Spatial Processes: Models and Applications. London: Pion.

Cong Zhentao, Zhou Haiying, Lei Zhidong et al., 2003. Analyses and simulations of the water transfer from the lower Tarim River. Advances in Water Science, 14(3): 276-279. (in Chinese)

Cui Gonghao, Wu Jin, 1990. The spatial structure and development of Chinese urban fringe. Acta Geographica Sinica, 45(4): 399-411. (in Chinese)

Cui Peng, 1992. Studies on condition and mechanism of debris flow initiation by means of experiment. Chinese Science Bulletin, 37(9): 759-763.

Cui Peng, He Siming, Yao Lingkan et al., 2011. Formation Mechanism and Risk Control of Mountain Disaster in Wenchuan Earthquake. Beijing: Science Press. (in Chinese)

Cui Peng, Liu Suqing, Tang Bangxing et al., 2005. Research and Prevention of Debris Flow in National Parks. Beijing: Science Press. (in Chinese)

Cui Peng, Zhou Gordon, Zhu Xinghua et al., 2013. Scale amplification of natural debris flows caused by cascading landslide dam failures. Geomorphology, 182: 173-189.

Cui Peng, Zou Qiang, Xiang Lingzhi et al., 2013. Risk assessment of simultaneous debris flows in mountain townships. Progress in Physical Geography, 37(4): 516-542.

Deng Mingjiang, 2009. Water management strategy of Tarim River Basin. China Water Resources, (21): 32-34, 36. (in Chinese)

Deng Mingjiang, Zhou Haiying, Xu Hailiang et al., 2016. Research on the ecological operation in the lower reaches of Tarim River based on water conveyance. Scientia Sinica (Technologica), 46(8): 864-876. (in Chinese)

Di Kun, Xu Xinwen, Lei Jiaqiang et al., 2005. Analysis on the growth of shelterbelt plants growing under different local conditions. Arid Zone Research, 22(3): 312-316. (in Chinese)

Diggle P J, 2003. Statistical Analysis of Spatial Point Patterns. 2nd ed. London: Edward Arnold.

Dong Zhibao,1998. Establishing statistic model of wind erosion on small watershed basis. Bulletin of Soil and Water Conservation, 18(5): 55-62. (in Chinese)

Dregne H E, 2002. Land degradation in the drylands. Arid Land Research and Management, 16: 99-132.

Dutilleul P R L, 2011. Spatio-temporal Heterogeneity: Concepts and Analysis. Cambridge: Cambridge University Press.

Dyson-Hudson R, 1983. Desertification as a social problem. Science, 221(4618): 1365-1366.

Fan Jie, 2015. Draft of major function oriented zoning of China. Acta Geographica Sinica, 70(2): 186-201. (in Chinese)

Fan Zili, 1979. Natural environmental protection in Tarim River Basin. Environmental Protection of Xinjiang, (2): 1-6. (in Chinese)

Fang Hui, Wu Xiaoxu, Zou Xueyong et al., 2018. An integrated simulation-assessment study for optimizing wind barrier design. Agricultural and Forest Meteorology, 263: 198-206.

Fang Weihua, Wang Jing'ai, Shi Peijun, 2011. Comprehensive Risk Prevention: Database, Risk Map and Network Platform. Beijing: Science Press. (in Chinese)

Feddema J J, Oleson K W, Bonan G B et al., 2005. The importance of land-cover change in simulating future climates. Science, 310(5754): 1674-1678.

Feng Z M, Yang Y Z, Zhang Y Q et al., 2005. Grain-for-Green policy and its impacts on grain supply in West China. Land Use Policy, 22(4): 301-312.

Feng Zhiming, Zhang Pengtao, Yang Yanzhao, 2003. The scale of land conversion from farmland to forest or 
grassland, the grain response to it, and the relevant proposals in Northwest China. Geographical Research, 22(1): 105-113. (in Chinese)

Foley J A, DeFries R, Asner G P et al., 2005. Global consequences of land use. Science, 309(5734): 570-574.

Fotheringham A S, Brunsdon C, 2000, Charlton M E. Quantitative Geography: Perspectives on Spatial Data Analysis. London: SAGE Publications.

Fu Bojie, 2016. Effects of soil and water conservation by land utilization and landscape project. Land Development and Engineering Research, (3): 41-50. (in Chinese)

$\mathrm{Fu}$ Bojie, 2018. Thoughts on the recent development of physical geography. Progress in Geography, 37(1): 1-7. (in Chinese)

Fu Bojie, Chen Liding, Ma Cheng, 1997. The index system and method of land sustainable use evaluation. Journal of Natural Resources, 12(2): 113-118. (in Chinese)

Fu Bojie, Liu Guohua, Chen Liding et al., 2001. Scheme of ecological regionalization in China. Acta Ecologica Sinica, 21(1): 1-6. (in Chinese)

$\mathrm{Fu}$ Bojie, Zhao Wenwu, Chen Liding, 2006. Progress and perspective of geographical-ecological processes. Acta Geographica Sinica, 61(11): 1123-1131. (in Chinese)

Future Earth. Future Earth initial design report, 2013. http://www.futureearth.org/media/future-earth-initial- design-report.

Gao Shangyu, Zhang Chunlai, Zou Xueyong et al., 2012. Benefits of Beijing-Tianjin Sand Source Control Engineering. Beijing: Science Press. (in Chinese)

Ge Quansheng, Zhao Mingcha, Zheng Jingyun et al., 2003. Division of the terrestrial system in China: A case study from Huang's theory on terrestrial system science. Scientia Geographica Sinica, 23(1): 1-6. (in Chinese)

Ge Quansheng, Zou Ming, Zheng Jingyun, 2008. Integrated Assessment of Natural Disaster Risks in China. Beijing: Science Press. (in Chinese)

Geng Kuanhong, 1959. Blown-sand wind and mobile sand. Acta Geographica Sinica, 25(1): 21-39. (in Chinese)

Getis A, Ord J K, 1992. The analysis of spatial association by distance statistics. Geographical Analysis, 24(3): 189-206.

Goldstein H, 2011. Multilevel Statistical Models. 4th ed. New York: Wiley.

Gong Shiyang, Jiang Deqi, 1979. Soil erosion and its control in small watershed of the Loess Plateau. Science in China, Ser. A, 22(11): 1302-1314.

Goudie A S, 2014. Desert dust and human health disorders. Environment International, 63: 101-113.

Griggs D, Stafford-Smith M, Gaffney O et al., 2013. Policy: Sustainable development goals for people and planet. Nature, 495: 305-307.

Guan Junwei, 2001. The subject system and prospect of soil and water conservation in China. Journal of Beijing Forestry University, 24(5/6): 273-276. (in Chinese)

Guo Huaming, Guo Qi, Jia Yongfeng et al., 2013. Chemical characteristics and geochemical processes of high arsenic groundwater in different regions of China. Journal of Earth Sciences and Environment, 35(3): 83-96. (in Chinese)

Guo Yanan, Li Hairong, Yang Linsheng et al., 2017. The relationship between environment selenium characteristic and distribution of Kaschin-Beck disease in the Yarlung Zangbo River banks. Chinese Journal of Endemiology, 36(7): 494-497. (in Chinese)

Haining R, 1990. Spatial Data Analysis in Environmental and Social Sciences. Cambridge: Cambridge University Press.

Haining R, 2003. Spatial Data Analysis: Theory and Practice. Cambridge: Cambridge University Press.

He Daliang, Zou Bengong, Li Changzhi et al., 1986. A preliminary study of the experiment of the physical process of ground surface erosion in wind tunnel. Journal of Desert Research, 6(1): 25-31. (in Chinese)

Hou Shaofan, Wang Wuyi, Li Hairong et al., 2002. Study on the geographically epidemic character of arsenism and its countermeasures. Progress in Geography, 21(4): 391-400. (in Chinese)

Hou Shaofan, Zhu Zhenyuan, 1984. A study of the relation between the whole blood selenium content of the population and Kaschin-Beck Disease in the low selenium regions in China. Geographical Research, 3(2): 14-23. (in Chinese)

Hou Xueyu, 1988. The Regionalization of Natural Ecosystems in China and the Strategy in Macro-agricultural 
Development. Beijing: Science Press. (in Chinese)

Hou Xueyu, Jiang Shu, Chen Changdu et al., 1963. Suggestion concerning the developmental direction of agriculture, forestry, animal husbandry, sideline production and fishery in different natural regions of China. Chinese Science Bulletin, 8(9): 8-26. (in Chinese)

Huang Bingwei, 1959. Draft of overall natural regionalization of China. Chinese Science Bulletin, (18): 594-602. (in Chinese)

Huang Bingwei, 2003. Notable issues on the work of regionalization in the new age. In: Editing Committee of Huang Bingwei Collection. Integrated Research in Physical Geography: Selected Papers of Huang Bingwei. Beijing: The Commercial Press. (in Chinese)

Huang Bingwei, Xu Yuexian, Wu Kai et al., 1993. Geography and Sustainable Agriculture. Beijing: China Meteorological Press. (in Chinese)

Huang Bingwei, Zuo Dakang, Chen Fazu, 1990. Field experimentation of physical geography in China. Acta Geographica Sinica, 45(2): 225-234.

Huang Fuxiang, Niu Haishan, Wang Mingxing et al., 2001. The relationship between vegetation cover and sand transport flux at Mu Us sandland. Acta Geographica Sinica, 56(6): 700-710. (in Chinese)

Huang Wei, Yan Jingjing, Liu Chang et al., 2019. Changes in climate regimes over China based on a high-resolution dataset. Science Bulletin, 64(6): 377-379.

Jia Yanan, Yuan Daoxian, 2003. The impact of land use change on karst water in Shuicheng Basin of Guizhou Province. Acta Geographica Sinica, 58(6): 831-838. (in Chinese)

Jiang Dingsheng, 1997. Soil Erosion and Control Models in the Loess Plateau. Beijing: China Water \& Power Press. (in Chinese)

Jie Yaowen, Chen Fahu, 2008. Development and Evolution of Minqin Oasis-Land Use/Land Cover Change in Recent 2000 Years. Beijing: Science Press. (in Chinese)

Jin Yinlong, Liang Chaoke, He Gongli et al., 2003. Study on distribution of endemic arsenism in China. Journal of Hygiene Research, 32(6): 519-540. (in Chinese)

Kulldorff M, 1997. A spatial scan statistic. Communications in Statistics: Theory and Methods, 26: $1481-1496$.

Li Bingwen, Xu Xinwen, Lei Jiaqiang et al., 2008. Site type classification of ecological project of highway protective forest in Tarim Desert. Chinese Science Bulletin, 53(Suppl. 2): 25-32. (in Chinese)

Li Hairong, Yang Linsheng, Tan Jian'an et al., 2017. Progress on selenium deficiency in geographical environment and its health impacts in China. Current Biotechnology, 7(5): 381-386. (in Chinese)

Li Hairong, Yang Linsheng, Wang Wuyi et al., 2001. Medical geographical evaluation on 150 years plague epidemic. Progress in Geography, 20(1): 73-80. (in Chinese)

Li Hongzhong, Li Shengyu, Lei Jiaqiang et al., 2005. Experimental study on afforestation irrigated with saltwater with different mineralizations in the Taklimakan Desert. Arid Land Geography, 28(3): 305-310. (in Chinese)

Li Huqun, Long Buyun, Zhou Rongnian et al., 1990. A study on the biomass of the Tamarix communities and their management and utilization in Xinjiang. Acta Phytoecologica et Geobotanica Sinica, 14(4): 366-372. (in Chinese)

Li Jiyun, Chen Daizhong, Ren Shangxue et al., 1991. Effect of applying selenium to increase its content in food on the prevention and cure of big bone season. Chinese Journal of Endemiology, 10(2): 69-75. (in Chinese)

Li Mingxing, Ma Zhuguo, 2012. Soil moisture-based study of the variability of dry-wet climate and climate zones in China. Chinese Science Bulletin, 57(28/29): 2740-2754. (in Chinese)

Li Ribang, Tan Jianan, Wang Wuyi et al., 1999. Study on increasing selenium flux in food chain to control Kaschin-Beck disease and Keshan disease. Acta Geographica Sinica, 54(2): 158-164. (in Chinese)

Li Shunjiang, Li Wei, Hu Xia et al., 2008. Distribution of Kashin-Beck disease (KBD) and its relation to selenium content in soil-plant-animal (human being) ecosystem in Tibet. Chinese Journal of Ecology, 27(12): 2167-2170. (in Chinese)

Li Xiubin, Zhao Yuluan, 2011. Forest transition, agricultural land marginalization and ecological restoration. China Population, Resources and Environment, 21(10): 91-95. (in Chinese)

Li Yangbing, Xie Deti, 2001. Features of water-stable soil aggregate structure under different land use in karst mountains. Journal of Soil and Water Conservation, 15(4): 122-125. (in Chinese)

Li Yong, Zhu Xianmo, Tian Jiying, 1991. Effectiveness of plant roots to increase the anti-scourability of soil on 
the Loess Plateau. Chinese Science Bulletin, 36(24): 2077-2082.

Li Yonghua, Wang Wuyi, 2001. Environmental dose-effects of fluoride in endemic fluorosis of drinking type areas. Chinese Journal of Control of Endemic Diseases, 16(5): 262-265. (in Chinese)

Li Yushan, 1999. Fundamental experiences for harness and development in the Loess Plateau of China. Journal of Soil and Water Conservation, 5(2): 51-57. (in Chinese)

Lin Chao, 1954. Outline of physical regionalization of China (abstract). Acta Geographica Sinica, 20(4): 395-418. (in Chinese)

Ling Yuquan, Gao Pengxun, Jin Jiong et al., 1985. Characteristics of desertification and its developmental trend in the lower reaches of Tarim River. Journal of Desert Research, (1): 5-17, 2. (in Chinese)

Liu Baoyuan, Xie Yun, Zhang Keli, 2001. Erosion Prediction Model. Beijing: Science and Technology of China Press. (in Chinese)

Liu Guobin, Shangguan Zhouping, Yao Wenyi et al., 2017. Ecological effects of soil conservation in Loess Plateau. Bulletin of Chinese Academy of Sciences, 32(1): 11-19. (in Chinese)

Liu Hua, Niu Fujun, Niu Yonghong et al., 2011. Study of design of filling material and setting anti-frost layer for high-speed railway roadbed in seasonally frozen regions. Chinese Journal of Rock Mechanics and Engineering, 30(12): 2549-2557. (in Chinese)

Liu Jianshan, 1953. Preliminary analysis of soil and water loss test in Tianshui. Chinese Science Bulletin, (12): 59-65. (in Chinese)

Liu Jiyuan, Liu Mingliang, Zhuang Dafang et al., 2001. Study on spatial pattern of recent land-use change in China. Science in China (Series D), 32(12): 1031-1040. (in Chinese)

Liu Jiyuan, Ning Jia, Kuang Wenhui et al., 2018. Spatio-temporal patterns and characteristics of land-use change in China during 2010-2015. Acta Geographica Sinica, 73(5): 789-802. (in Chinese)

Liu Peijun, 1989. Comprehensive survey of remote sensing in Tarim River Basin. Remote Sensing Technology and Application, (4): 55-57, 20. (in Chinese)

Liu Yanhua, Ge Quansheng, Wu Wenxiang, 2005. Risk Management: Challenges of the New Century. Beijing: China Meteorological Press. (in Chinese)

Liu Yinhan, 1983. Research on the division, classification and grading of land resources in China. Journal of Shaanxi Normal University, (1): 187-196. (in Chinese)

Liu Yunpeng, Tan Jianan, Shen Erli, 2000. Atlas of Plague and the Environment of the People's Republic of China. Beijing: Science Press. (in Chinese)

Liu Yuzhang, Dong Guangrong, Li Changzhi, 1992. Study on some factors influencing soil erosion by wind tunnel experiment. Journal of Desert Research, 12(4): 41-49. (in Chinese)

Liu Zhenxing, 1960. Study on blown-sand issue (II): Preliminary study on dune movement under wind effect. Journal of Meteorology, 31(1): 84-91. (in Chinese)

Lu Zongfan, 1997. Chinese Loess Plateau Eco-Agriculture. Xi'an: Shaanxi Science and Technology Press. (in Chinese)

Luo Kaifu, 1954. Chinese physical geography draft. Acta Geographica Sinica, 20(4): 379-394. (in Chinese)

Ma Danyang, Deng Haoyu, Yin Yunhe et al., 2019. Sensitivity of arid/humid patterns in China to future climate change under a high-emissions scenario. Journal of Geographical Sciences, 29(1): 29-48.

Ma Wei, Cheng Guodong, Wu Qingbai, 2002. Preliminary study on technology of cooling foundation in permafrost regions. Journal of Glaciology and Geocryology, 24(5): 579-587. (in Chinese)

Ma Wei, Cheng Guodong, Wu Qingbai, 2009. Construction on permafrost foundations: Lessons learned from the Qinghai-Tibet railroad. Cold Regions Science and Technology, 59(1): 3-11.

Ma Zhuguo, Fu Congbin, 2005. Decadal variations of arid and semi-arid boundary in China. Chinese Journal of Geophysics, 48(3): 519-525. (in Chinese)

Macias-Fauria M, 2018. Satellite images show China going green. Nature, 553(7689): 411-413.

Matheron G, 1963. Principles of geostatistics. Economic Geology, 58: 1246-1266.

Mei Fanmin, 2013. Experimental Observation and Numerical Simulation of Wind Erosion Dust Release in Typical Regions of Northern China. Xi'an: Press of Northwestern Polytechnical University. (in Chinese)

Ning Jia, Liu Jiyuan, Zhao Guosong, 2015. Spatio-temporal characteristics of disturbance of land use change on major ecosystem function zones in China. Chinese Geographical Science, 25(5): 523-536. 
Openshaw S, 1984. The Modifiable Areal Unit Problem: Concepts and Techniques in Modern Geography. Norwich: Geo Books.

Pang Chunhao, 1990. Model of harnessing saline-alkali in depression in the Huang-Huai-Hai alluvial plain: Take Beiqiuwa in Yucheng county, for example. Geographical Research, 9(1): 47-54. (in Chinese)

Qi Wei, Bai Wanqi, Zhang Yili et al., 2016. Effects of ecological engineering on net primary production in the Chang Tang and Sanjiangyuan national nature reserves on the Tibetan Plateau. Biodiversity Science, 24(2): 127-135. (in Chinese)

Qin Dahe, 2014. Climate change science and sustainable development. Progress in Geography, 33(7): 874-883. (in Chinese)

Qin Dahe, Zhang Jianyun, 2015. Shan Chun et al. China National Assessment Report on Risk Management and Adaptation of Climate Extremes and Disasters. Beijing: Science Press. (in Chinese)

Qiu Baojian, 1986. A scheme for the comprehensive natural division of the country's agriculture. Journal of Henan University(Natural Science), 16(1): 21-28. (in Chinese)

Ren Mei'e, Yang Renzhang, 1961. Natural regionalization in China. Acta Geographica Sinica, 27: 66-74. (in Chinese)

Research Team of Environment and Endemic Disease (RTEED), 1986. Studies on low selenium belt in China and pathogeny of Keshan and Kaschin-Beck diseases. Environmental Science, 7(4): 89-93. (in Chinese)

Reynolds J F, Smith D M S, Lambin E F et al., 2007. Global desertification: Building a science for dry land development. Science, 316: 847-851.

Ripley B D, 1977. Modelling spatial patterns. Journal of Royal Statistical Society B, 39(2): 172-192.

Sha Wanying, Shao Xuemei, Huang Mei, 2002. Climate warming in China since the 1980s and its impact on natural area boundaries. Science in China (Series D), 32(4): 317-326. (in Chinese)

Shao Quanqin, Zhao Zhiping, Liu Jiyuan et al., 2010. The characteristics of land cover and macroscopical ecology changes in the source region of three rivers on Qinghai-Tibet Plateau during last 30 years. Geographical Research, 29(8): 1439-1451. (in Chinese)

Shen Yuancun, Guo Huancheng, 1981. A National Conference on 1:1 Million Land Type Maps and Land Use Maps held in Chengdu. Acta Geographica Sinica, 36(2): 225-227. (in Chinese)

Shi Gangqiang, Zhao Shiyun, Li Xianming et al., 2014. The frost heaving deformation of high-speed railway subgrades in cold regions: Monitoring and analyzing. Journal of Glaciology and Geocryology, 36(2): 360-368. (in Chinese)

Shi Peijun, 2005. Theory and practice on disaster system research in a fourth time. Journal of Natural Disasters, 14(6): 1-7. (in Chinese)

Shi Peijun, 2011. Atlas of Natural Disaster Risk of China. Beijing: Science Press. (in Chinese)

Shi Peijun, Li Ning, Ye Qian et al., 2009. Research on global environmental change and integrated disaster risk governance. Advances in Earth Science, 24(4): 428-434. (in Chinese)

Shi Peijun, Lv Lili, Wang Ming et al., 2014. Disaster system: Disaster cluster, disaster chain and disaster compound. Journal of Natural Disasters, 23(6): 1-12. (in Chinese)

Shi Peijun, Wang Ming, Hu Xiaobing et al., 2014. Integrated risk governance consilience mode of social-ecological systems. Acta Geographica Sinica, 69(6): 863-876. (in Chinese)

Shi Peijun, Yan Ping, Yuan Yi et al., 2004. Wind erosion research in China: Past, present and future. Progress in Physical Geography, 28(3): 366-386.

Shi Yulin, 1979. Land resource classification system of three maps of one millionth land resource in Northeast China. Resources Science, (1): 77-90. (in Chinese)

Song Changqing, Leng Shuying, 2005. Characteristics and trend of modern geography and progresses of geographical research in China. Advances in Earth Science, 20(6): 5-9. (in Chinese)

Song X P, Hansen M C, Stehman S V et al., 2018. Global land change from 1982 to 2016. Nature, 560(7720): 639-643.

State Forestry Administration (SFA), 2015. A Bulletin of Status Quo of Desertification and Sandification in China. Beijing: State Forestry Administration. (in Chinese)

Su Biyao, 1981. Preliminary discussion on land quality evaluation method in large scale mapping: A case study of Southern Jiangsu. Journal of Nanjing Normal University (Natural Science Edition), (2): 45-52. (in Chinese) 
Su Buda, Huang Jinlong, Fischer T et al., 2018. Drought losses in China might double between the $1.5^{\circ} \mathrm{C}$ and 2.0

${ }^{\circ} \mathrm{C}$ warming. Proceedings of the National Academy of Sciences, 115(42): 10600-10605.

Sun Honglie, 2005. Ecosystem of China. Beijing: Science Press, 1104-1111. (in Chinese)

Sun Honglie, 2006. China Ecosystem Research Network provides technological support for ecosystem assessment. Resources Science, 28(4): 2-10. (in Chinese)

Survey Report on the Development of Field Stations (SRDFS) of the Chinese Academy of Sciences, 2014. http://www.cas.cn/ggzy/kycx/ywtz/201409/t20140905_4198278. (in Chinese)

Sweeting M M, 1993. Reflections on the development of karst geomorphology in Europe and a comparison with its development in China. Zeitschrift fur Geomorphologie, 37: 127-138.

Tan Jianan, 1989. Environmental Selenium and Health. Beijing: People's Medical Publishing House. (in Chinese)

Tan Jianan, Zhu Wenyu, Wang Wuyi et al., 2002. Selenium in soil and endemic diseases in China. The Science of the Total Environment, 284: 227-235.

Tang Bangxing, Zhou Bifan, Wu Jishan et al., 2000. Debris Flows in China. Beijing: Science Press. (in Chinese)

Tang Keli, 2004. Soil and Water Conservation in China. Beijing: Science Press, 80-113. (in Chinese)

The Committee of Endemic Diseases and Their Environments (CEDTE) in the People's Republic of China, 1989. Atlas of Endemic Diseases and Their Environments in the People's Republic of China. Beijing: Science Press. (in Chinese)

The Group of Environment and Endemic Disease (GEED), 1979. The Keshan disease in China: A study of the geographical epidemiology. Acta Geographica Sinica, 34(2): 85-103. (in Chinese)

The Group of Environment and Endemic Disease (GEED), 1981. The relationship between the distribution of Keshan disease and the selenium content of food grains as a factor of chemical geographical environment. Acta Geographica Sinica, 36(4): 369-376. (in Chinese)

The Group of Environment and Endemic Disease, 1985. The characteristics of geographical epidemiology for Kaschin-Beck's disease in China and its pathogenicity. Scientia Geographica Sinica, 5(1): 1-8. (in Chinese)

The Leading Office of First-ever Nationwide Water Resources Survey of the State Council (LOFNWRS), 2010. No.6 Training Materials of First-ever Nationwide Water Resources Survey. Beijing: China Water \& Power Press: 4-117. (in Chinese)

Tian Kuixiang, 1992. Integrated Management Techniques of Coastal Water Shortage Salinized Salty Areas. Beijing: Science Press: 6-9. (in Chinese)

Tian Yongku, 1982. Briefing on comprehensive investigation of Tarim River Basin. Agricultural Economy, (6): 47. (in Chinese)

Tong Xiaowei, Brandt M, Yue Yuemin et al., 2018. Increased vegetation growth and carbon stock in China karst via ecological engineering. Nature Sustainability, 1: 44-50.

UNCCD, 1994. United Nations convention to combat desertification in countries experiencing serious drought and/or desertification, particularly in Africa. International Legal Materials, 33: 1328-1366.

United Nations, 2015. Transforming Our World: The 2030 Agenda for Sustainable Development. New York: United Nations, 3-36.

Upton G, Fingleton B, 1985. Spatial Data Analysis by Example. New York: Wiley.

Wan Jun, Cai Yunlong, Lu Yunge et al., 2003. Soil erosion risk assessment in karst area: Case study in Guanling County of Guizhou Province. Research of Soil and Water Conservation, 10(3): 148-153. (in Chinese)

Wang Jinfeng, Ge Yong, Li Lianfa et al., 2014. Spatiotemporal data analysis in geography. Acta Geographica Sinica, 69(9): 1326-1345. (in Chinese)

Wang Jinfeng, Li Xinhu, Christakos G et al., 2010. Geographical detectors-based health risk assessment and its application in the neural tube defects study of the Heshun region, China. International Journal of Geographical Information Science, 24(1): 107-127.

Wang Jinfeng, Xu Chengdong, 2017. Geodetector: Principle and prospective. Acta Geographica Sinica, 72(1): 116-134. (in Chinese)

Wang Jinfeng, Zhang Tonglin, Fu Bojie, 2016. A measure of spatial stratified heterogeneity. Ecological Indicators, 67: 250-256.

Wang Jing, Li Hairong, Yang Linsheng et al., 2017. Distribution and translocation of selenium from soil to highland barley in the Tibetan Plateau Kashin-Beck disease area. Environmental Geochemistry and Health, 39: 
221-229.

Wang Rende, Guo Zhongling, Chang Chunping et al., 2015. Quantitative estimation of farmland soil loss by wind-erosion using improved particle-size distribution comparison method (IPSDC). Aeolian Research, 19: $163-170$.

Wang Shaoling, Mi Haizhen, 1993. The change of permafrost under roadbed with asphalt pavement along the Qinghai-Tibet Highway. Journal of Glaciology and Geocryology, 24(1): 10-15. (in Chinese)

Wang Shijie, 2002. Concept deduction and its connotation of karst rocky desertification. Carsologica Sinica, 21(2): 101-105. (in Chinese)

Wang Shuangjie, Li Zhulong, Zhang Jinzhao et al., 2008. Highway Construction Technology on Permafrost Regions. Beijing: People's Communications Press. (in Chinese)

Wang Tao, Song Xiang, Yan Changzhen et al., 2011. Remote sensing analysis on aeolian desertification trend in northern China during 1975-2010. Journal of Desert Research, 31(6): 1351-1356. (in Chinese)

Wang T, Xue X, Zhou L et al., 2015. Combating aeolian desertification in northern China. Land Degradation \& Development, 26: 118-132.

Wang Xunming, Chen Fahu, Eardun H S et al., 2008. Desertification in China: An assessment. Earth-Science Reviews, 88: 188-206.

Wang Xunming, Dong Zhibao, Wu Shengzhi et al., 2001. A stochastic model for processes of soil wind erosion. Bulletin of Soil and Water Conservation, 21(1): 19-22. (in Chinese)

Wang Xunming, Yang Yi, Dong Zhibao et al., 2009. Responses of dune activity and desertification in China to global warming in the twenty-first century. Global and Planetary Change, 67: 167-185.

Wang Yue, 2001. The historical evolution and development countermeasures of soil and water conservation in China. Soil and Water Conservation in China, (11): 5-8. (in Chinese)

Wang Zhijian, 2002. Permafrost engineering in Qinghai-Tibet Railway construction. Chinese Railways, (12): 31-37. (in Chinese)

Wang Zhiguo, Zhang Chao, Ji Qiang et al., 2016. Soil and water conservation regionalization and its application in China. Science of Soil and Water Conservation, 14(6): 101-106.

Wang Zunqin, 1987. Research on Agricultural Development Strategy and Comprehensive Management of Natural Wenyanqu Basin. Beijing: Science Press, iii-iv. (in Chinese)

Wei Binggan, Yu Jiangping, Kong Chang et al., 2018. Effects of arsenic methylation and metabolism on the changes of arsenic-related skin lesions. Environmental Science and Pollution Research, 25: 24394-24402.

Wu Chuanjun, 1979. Land use survey and mapping for agricultural modernization. Resources Science, (2): 39-47. (in Chinese)

Wu Jingmin, Wang Shuangjie, Zhang Jinzhao, 2005. Highway Engineering in Permafrost Area. Beijing: People's Communication Press. (in Chinese)

Wu Qingbai, Liu Yongzhi, Zhang Jianming et al., 2002. A review of recent frozen soil engineering in permafrost regions along Qinghai-Tibet Highway, China. Permafrost and Periglacial Processes, 13(3): 199-205.

Wu Qingbai, Tong Changjiang, 1995. Permafrost change and stability of Qinghai-Tibet Highway. Journal of Glaciology and Geocryology, 17(4): 350-355. (in Chinese)

Wu Qingbai, Zhao Shiyun, Ma Wei et al., 2007. Qinghai-Xizang railroad construction in permafrost regions. ASCE Journal of Cold Regions Engineering, 21(2): 60-67.

Wu Shaohong, 1998. The basic designation of integrated zonation: Case study of Chaidam Basin. Geographical Research, 17(4): 367-374. (in Chinese)

Wu Shaohong, Liu Lulu, Liu Yanhua et al., 2019. The Belt and Road: Geographical pattern and regional risks. Journal of Geographical Sciences, 29(4): 483-495.

Wu Shaohong, Liu Weidong, 2005. An integrated approach to classification of territorial systems: A case study of Tibetan Plateau. Geographical Research, 24(2): 169-177. (in Chinese)

Wu Shaohong, Liu Wenzheng, Pan Tao et al., 2016. Amplitude and velocity of the shifts in the Chinese terrestrial surface regions from 1960 to 2011. Chinese Science Bulletin, 61(19): 2187. (in Chinese)

Wu Shaohong, Pan Tao, He Shanfeng, 2011. Primary study on the theories and methods of research on climate change risk. Climate Change Research, 7(5): 363-368. (in Chinese)

Wu Shaohong, Pan Tao, Liu Yanhua et al., 2017. Comprehensive climate change risk regionalization of China. 
Geographica Sinica, 72(1): 3-17. (in Chinese)

Wu Shaohong, Pan Tao, Yang Qinye, 2014. Risk Pattern and Prevention of Major Meteorological and Hydrological Disasters in China. Beijing: Science Press. (in Chinese)

Wu Shaohong, Zheng Du, Yin Yunhe et al., 2010. Northward-shift of temperature zones in China's eco-geographical study under future climate scenario. Journal of Geographical Sciences, 20(5): 643-651.

$\mathrm{Wu}$ Xiaoxu, Zou Xueyong, Zheng Zhongquan Charlie et al., 2011. Field measurement and scaled-down wind-tunnel model measurement of airflow field over a barchan dune. Journal of Arid Environments, 75: 438-445.

Wu Zheng, 1962. Preliminary study on wind sand and soil erosion in Hotan area, Xinjiang. In: Geographical Society of China. Abstract of the Symposium on Geomorphology, 1961. Beijing: Science Press: 125-127. (in Chinese)

Wu Zheng, 2003. Sandstorm Landform and Desertification Control Engineering. Beijing: Science Press. (in Chinese)

Wu Zheng, 2009a. China Desert and Its Control. Beijing: Science Press. (in Chinese)

Wu Zheng, 2009b. Deserts in China and their management over the last 50 years. Arid Zone Research, 26(1): 1-7. (in Chinese)

Wu Zheng, Ling Yuquan, 1965. A preliminary study on some laws of aeolian sand movement and its prevention. In: Desert Control Group of Academia Sinica. Research on Desertification Control. Beijing: Science Press: 7-14. (in Chinese)

Xi Chengfan, Zhang Junmin, Qiu Baojian et al., 1986. Outline of China's Natural Divisions. Beijing: Science Press, 1984. [12] Qiu Baojian. A scheme for the comprehensive natural division of the country's agriculture. Journal of Henan University (Natural Science), 16(1): 21-28. (in Chinese)

Xie Yaowen, Chen Fahu, Qi Jiaguo, 2009. Past desertification processes of Minqin oasis in arid China. International Journal of Sustainable Development and World Ecology, 16(6): 417-426.

Xin Shuzhi, Jiang Deqi, 1982. Introduction to Soil and Water Conservation in China. Beijing: Agricultural Press. (in Chinese)

$\mathrm{Xu}$ Xinwen, Li Bingwen, Wang Xiaojing, 2006. Study on sandy irrigation (technology) in hinterland of Taklimakan Desert. Chinese Science Bulletin, 51(Suppl. 1): 133-136. (in Chinese)

$\mathrm{Xu}$ Yan, Zhang Fengrong, Yan Guoqiang et al., 2005. The principles, criteria and methods for assessing policy of dynamic balance of total amount of cultivated land. China Land Science, (1): 44-48. (in Chinese)

$\mathrm{Xu}$ Yueqing, Cai Yunlong, 2006. Economic loss analysis on soil erosion and estimation of its values: A case study of Maotiaohe basin, Guizhou province. Resources and Environment in the Yangtze Basin, 15(4): 470-474. (in Chinese)

$\mathrm{Xu}$ Yueqing, Li Shuangcheng, Cai Yunlong, 2006. Spatial simulation using GIS and artificial neural network for regional poverty: A case study of Maotiaohe watershed, Guizhou province. Progress in Geography, 25(3): 79-85. (in Chinese)

Xue Jie, Gui Dongwei, Lei Jiaqiang et al., 2017. Model development of a participatory Bayesian network for coupling ecosystem services into integrated water resources management. Journal of Hydrology, 554: 50-65.

Yan Ping, Dong Guangrong, Zhang Xinbao et al., 2001. Preliminary results of using ${ }^{137} \mathrm{Cs}$ to study wind erosion in the Qinghai-Tibet Plateau. Journal of Arid Environments, 47(4): 443-452.

Yan Qinshang, 1954. Moving sand dune and its transformation in Yulin, northern Shaanxi Province. Chinese Science Bulletin, (11): 28-34. (in Chinese)

Yang Dongliang, Liu Wei, Wang Jingpu et al., 2018. Wind erosion forces and wind direction distribution for assessing the efficiency of shelterbelts in northern China. Aeolian Research, 33: 44-52.

Yang Jianping, Ding Yongjian, Chen Rensheng et al., 2002. The interdecadal fluctuation of dry and wet climate boundaries in China in recent 50 years. Acta Geographica Sinica, 57(6): 655-661. (in Chinese)

Yang Jiuchun, Zhang Shuwen, Chang Liping et al., 2017. Gully erosion regionalization of black soil area in northeastern China. Chinese Geographical Science, 27(1): 78-87. (in Chinese)

Yang Linsheng, Chai Yuanqing, Yu Jiangping et al., 2017. Associations of arsenic metabolites, methylation capacity, and skin lesions caused by chronic exposure to high arsenic in tube well water. Environmental Toxicology, 32: $28-36$. 
Yang Linsheng, Chen Rugui, Wang Wuyi et al., 2000. The temporal and spatial distribution of the plague foci since 1840 in China. Geographical Research, 19(3): 243-248. (in Chinese)

Yang Linsheng, Lv Yao, Li Hairong et al., 2005. The relationship between Kaschin-beck diseases distribution and mountain luvisols' distribution in Tibet. Journal of Mountain Science, 23(4): 385-390. (in Chinese)

Yang Linsheng, Wang Wuyi, Hou Shaofan et al., 2002. Effects of selenium supplementation on arsenism: An intervention trial in Inner Mongolia. Environmental Geochemistry and Health, 24(4): 359-374.

Yang Linsheng, Wang Wuyi, Tan Jianan et al., 2010. Overview on the research works in the field of environmental geography and human health. Geographical Research, 29(9): 1571-1583. (in Chinese)

Yang Qinye, Zheng Du, 2010. Huang Bingwei and the study of physical geography. Acta Geographica Sinica, 65(9): 1146-1150. (in Chinese)

Ye Duzheng, Jiang Yundi, Dong Wenjie, 2003. The northward shift of climatic belts in China during the last 50 years and the corresponding seasonal responses. Advances in Atmospheric Sciences, 20(6): 959-967.

Ye Yangsheng, Wang Zhongjin, Cheng Aijun et al., 2007. Frost heave classification of railway subgrade filling material and the design of anti-freezing layer. China Railway Science, 28(1): 1-7. (in Chinese)

Yeh A G O, Li X, 1999. Economic development and agricultural land loss in the Pearl River Delta, China. Habitat International, 23(3): 373-390.

Yin Yunhe, Ma Danyang, Wu Shaohong, 2019. Enlargement of the semi-arid region in China from 1961 to 2010. Climate Dynamics, 52(1/2): 509-521.

Yu Guirui, Yu Xiubo, 2013. Chinese Ecosytem Research Network (CERN) and natural ecosystem protection. Bulletin of Chinese Academy of Sciences, 28(2): 275-283. (in Chinese)

Yu Jiangping, Wang Wuyi, Feng Fujian et al., 2004. Expiration of prevention action of coating technique on fluoride and sulfur pollution from civilian high-fluorine stone coal. China Environmental Science, 24(6): 662-664. (in Chinese)

Yu Renpei, 2001. Ideas about exploitation and utilization of saline soil resources. Chinese Journal of Soil Science, 32(Suppl. 2): 138-140. (in Chinese)

Yu Xinxiao, Chen Lihua, Zhang Zhiqiang et al., 2016. Water Conservation Forest Technology, Research and Demonstration. Beijing: Science Press. (in Chinese)

Yu Xinxiao, Zhang Xiaoming, Wu Sihong, 2006. The effect of vegetation and precipitation upon runoff and sediment production in sloping lands of loess area. Journal of Mountain in Science, 24(1): 19-26. (in Chinese)

Yuan Daoxian, 1997. Rock desertification in the subtropical karst of south China. Zeitschrift für Geomorphologie $N F$, 108: 81-90.

Yue Xiliu, Wu Shaohong, Yin Yunhe et al., 2018. Risk identification of seismic landslides by joint Newmark and Rockfall analyst models: A case study of roads affected by the Jiuzhaigou earthquake. International Journal of Disaster Risk Science, 9(3): 392-406.

Zhang Cheng, Yuan Daoxian, 2004. Hydrochemical variation of typical karst subterranean stream basin and its relationship with landuse change: A case study of Houzhai stream basin. Journal of Soil and Water Conservation, 18(5): 134-138. (in Chinese)

Zhang Chunlai, Zou Xueyong, Gong Jirui et al., 2004. Aerodynamic roughness of cultivated soil and its influences on soil erosion by wind in a wind tunnel. Soil \& Tillage Research, 75: 53-59.

Zhang Jinzhao, Li Zhulong, Wu Jingmin, 2000. Discussion on main factors about frozen subgrade stability. Highway, (2): 17-20. (in Chinese)

Zhang Jiquan, Li Ning, 2007. The Quantitative Method and Its Application of Risk Assessment and Management of Major Meteorological Disasters. Beijing: Beijing Normal University Press. (in Chinese)

Zhang Kecun, Qu Jianjun, Liao Kongtai et al., 2010. Damage by wind-blown sand and its control along Qinghai-Tibet Railway in China. Aeolian Research, 1(3/4): 143-146.

Zhang Xinbao, 2016. History, achievements, problems and suggested countermeasures of karst desertification control in Guizhou. Carsologica Sinica, 35(5): 497-502. (in Chinese)

Zhang Yili, Liu Linshan, Wang Zhaofeng et al., 2019. Spatial and temporal characteristics of land use and cover changes in the Tibetan Plateau. Chinese Science Bulletin, 64(9): 2685-2875. (in Chinese)

Zhang Yili, Qi Wei, Zhou Caiping et al., 2014. Spatial and temporal variability in net primary production of alpine grassland on Tibetan Plateau since 1982. Journal of Geographical Sciences, 24(2): 269-287. 
Zhao Hai, Sheng Yongwei, Zhang Jiawu et al., 2015. Oasis evolution processes and mechanisms in the lower reaches of Heihe River, Inner Mongolia, China since 1 ka ago. The Holocene, 25(3): 445-453.

Zhao Qiguo et al., 2002. Temporal-spatial Changes, Mechanism and Controlling Counter Measures of Soil Degradation in Hilly Red Soil Region of Eastern China. Beijing: Science Press. (in Chinese)

Zhao Qiguo, Yang Jinsong, Zhou Hua, 2011. "Ten Words" strategic policy for ensuring red line of farmland and food security in China. Soils, 43(5): 681-687. (in Chinese)

Zhao Songqiao, 1983. A new scheme for comprehensive physical regionalization in China. Acta Geographica Sinica, 38 (1): 1-10. (in Chinese)

Zhao Songqiao, Chen Chuankang, Niu Wenyuan, 1979. Thirty years in integrated physical geography in People's Republic of China. Acta Geographica Sinica, 46(3): 187-199. (in Chinese)

Zhao Xinyi, Zhang Huiyuan, Wan Jun, 2002. The impact of climatic change on the climate zones in the Qinghai-Tibetan Plateau. Scientia Geographica Sinica, 22(2): 190-195. (in Chinese)

Zhao Yuan, Ma Ligang, 2016. Discussion on distribution of soil and water conservation monitoring stations. Soil and Water Conservation in China, (1): 23-25. (in Chinese)

Zheng Du et al., 2008. Eco-geographical Region System of China. Beijing: The Commercial Press. (in Chinese)

Zheng Du, Fu Xiaofeng, 1999. A preliminary study on issues of integrated geographical regionalization. Scientia Geographica Sinica, 19(3): 193-197. (in Chinese)

Zheng Du, Yang Qinye, Wu Shaohong, 2015. Physical Geography in China: Introduction. Beijing: Science Press. (in Chinese)

Zhong Dunlun, Liu Shijian, Wang Chenghua et al., 1998. Research status and advance of catalogue and database (IS) for debris and landslides in China. In: Zhong Dunlun, Wang Chenghua, Xie Hong et al. Study on Catalogue Database and Regional Law for Debris and Landslides in China. Chengdu: Sichuan Science and Technology Press, 1-5. (in Chinese)

Zhou Bifan, 1995. Research and verification on mechanical model and motion equation for viscous debris flow. Science in China: Series B, 25(2): 196-203. (in Chinese)

Zhou Bifan, Li Deji, Luo Defu et al., 1991. The Guide of Debris Flow Prevention. Beijing: Science Press. (in Chinese)

Zhou Chenghu, Cheng Weiming, Qian Jinkai et al., 2009. Research on the classification system of digital land geomorphology of 1:1000000 in China. Journal of Geo-Information Science, 11(6): 707-724. (in Chinese)

Zhou Chenghu, Wan Qing, Huang Shifeng et al., 2000. A GIS-based approach to flood risk zonation. Acta eographica Sinica, 67(1): 15-24. (in Chinese)

Zhou Youwu, Qiu Guoqing, Guo Dongxin et al., 2000. Permafrost in China. Beijing: Science Press. (in Chinese)

Zhou Zhibin, Xu Xinwen, Lei Jiaqiang et al., 2006. Salt balance and movement of Tarim Desert Highway Shelterbelt irrigated by saline water. Arid Land Geography, 29(4): 470-475. (in Chinese)

Zhu Xianmo, 1989. Soil and Agriculture in the Loess Plateau. Beijing: Agricultural Science Press. (in Chinese)

Zhu Xianmo, 2006. Maintain soil reservoir and insure mountains beautiful of the Loess Plateau. Soil and Water Conservation in China, (1): 6-7. (in Chinese)

Zhu Zaichun, Piao Shilong, Myneni R B et al., 2016. Greening of the Earth and its drivers. Nature Climate Change, 6: 791-795.

Zhu Zhenda, 1979. Thirty years in research works on Chinese sandy deserts. Acta Geographica Sinica, 46(4): 305-314. (in Chinese)

Zhu Zhenda, 1994. The status and prospect desertification in China. Acta Geographica Sinica, 61(Suppl.1): 650-659. (in Chinese)

Zou Xueyong, Liu Yuzhang, Wu Dan et al., 1994. A study on some special ground wind erosion in the tunnel. Geographical Research, 13(2): 41-48. (in Chinese)

Zou Xueyong, Zhang Chunlai, Cheng Hong et al., 2014. Classification and representation of factors affecting soil wind erosion in a model. Advances in Earth Science, 29(8): 875-889. (in Chinese)

Zou Xueyong, Zhang Chunlai, Cheng Hong et al., 2018. Urban Sand Control Theory and Engineering. Beijing: Science Press. (in Chinese) 